\title{
Copyright
}

by

Hideyuki Amai

2016 
The Thesis Committee for Hideyuki Amai

Certifies that this is the approved version of the following thesis:

\section{EXPERIMENTAL STUDY ON AIR CHANGE EFFECTIVENESS IN MIXING VENTILATION}

\section{APPROVED BY \\ SUPERVISING COMMITTEE:}

Supervisor:

Atila Novoselac

Richard Corsi 


\title{
EXPERIMENTAL STUDY ON AIR CHANGE EFFECTIVENESS IN MIXING VENTILATION
}

by

Hideyuki Amai, B.Arch., M.E.

\author{
Thesis \\ Presented to the Faculty of the Graduate School of \\ The University of Texas at Austin \\ in Partial Fulfillment \\ of the Requirements \\ for the Degree of
}

Master of Science in Engineering

The University of Texas at Austin

May 2016 


\section{Acknowledgements}

I would like to take this opportunity to thank my advisor Dr. Atila Novoselac for his exceptional support and guidance, both during this research and in related pursuits. I have thoroughly enjoyed Dr. Novoselac's hands-on research approach and in sharing his joy for new discoveries in the laboratory. I am grateful to Dr. Richard Corsi for serving as a reader and for supporting this research. I would also like to thank Obayashi Corporation, for granting me support to pursue my graduate studies. 


\begin{abstract}

\section{EXPERIMENTAL STUDY ON AIR CHANGE EFFECTIVENESS IN MIXING VENTILATION}

\author{
Hideyuki Amai, M.S.E. \\ The University of Texas at Austin, 2016 \\ Supervisor: Atila Novoselac
}

Providing occupant comfort and health with minimized use of energy is the ultimate purpose of heating, ventilating and air conditioning (HVAC) system. Building ventilation directly affects indoor air quality, and it influences occupant's heath and productivity. Mixing ventilation is the most common air distribution system, and often the same diffusers provide space cooling and heating. Air distribution with all-air-heating is one of the major challenges for mixing ventilation as temperature stratification and corresponding low ventilation effectiveness may appear. The two objectives of this research were to: (1) provide design criterion for diffuser selection and location considering both thermal comfort and ventilation, emphasis on heating conditions. (2) assess the procedure of evaluating air change effectiveness in the current standard, especially focusing the variance of local air change effectiveness. The study used experimental measurements in a full-scale test room. $\mathrm{CO}_{2}$ tracer gas decay tests were conducted to simultaneously measure age of air at 18 locations in the test room with various types of ceiling diffusers, $T_{0.25} / L$ (air flow rates) and internal loads. 
Analysis of the experiments regarding first objective showed that the air change effectiveness was significantly decreased when $T_{0.25} / L$ went small under heating conditions. The range of air change effectiveness and the temperature effectiveness were 0.56 to 0.87 and 0.58 to 0.75 respectively within the recommended range of $T_{0.25} / L$ regarding ADPI. Regardless of diffuser type, air change effectiveness and the temperature effectiveness was close to or higher than 1.00 under cooling conditions. The range of $T_{0.25} / L$ that can achieve good mixing under heating condition was significantly shorter than the one under cooling mode. Regarding second objective, the variance analysis showed the vertical, horizontal and overall variance of local air change effectiveness was minimal in mixing ventilation. The variance of air change effectiveness in the occupied space of the room with ceiling diffusers was less than $16 \%$ in most of the cases, which is slightly larger than the experiments' uncertainty. Furthermore, the newly developed correlation of thermal effectiveness and air change effectiveness considered to be useful as an alternative method to interpret air change efficiency. 


\section{Table of Contents}

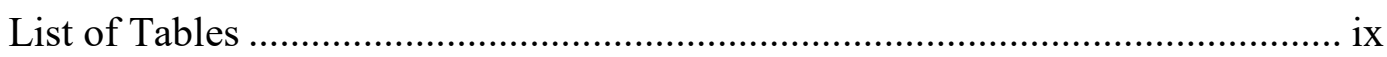

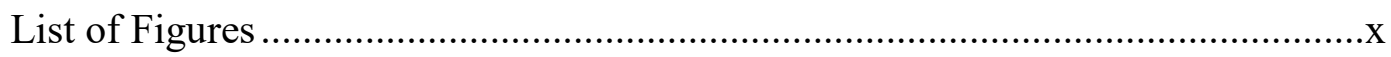

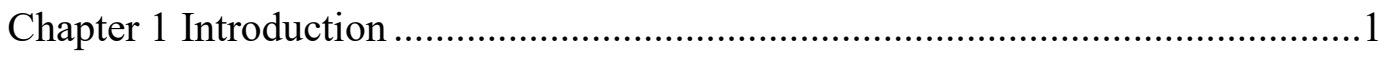

Chapter 2. Literature Review and Theoretical Background ....................................5

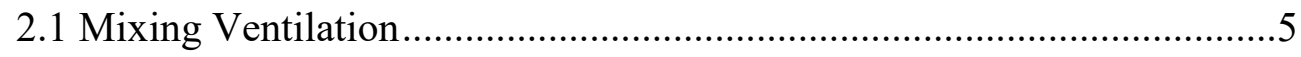

2.1.1 Influences of Inlet/Outlet Locations ............................................6

2.1.2 Influences of Internal Objects .....................................................

2.1.3 Ventilation Effectiveness under Heating Mode .............................8

2.2 Ventilation Effectiveness in Standards .................................................10

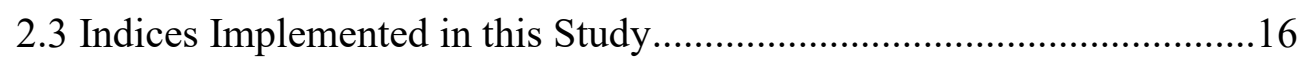

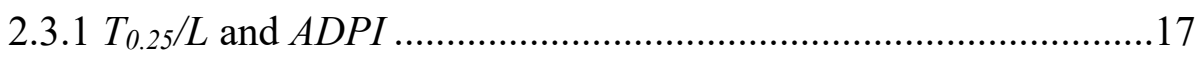

2.3.2 Air Change Effectiveness .......................................................17

2.3.3 Temperature Effectiveness.........................................................18

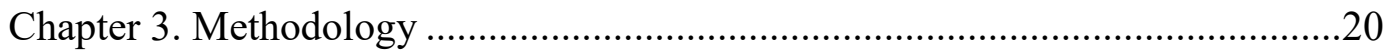

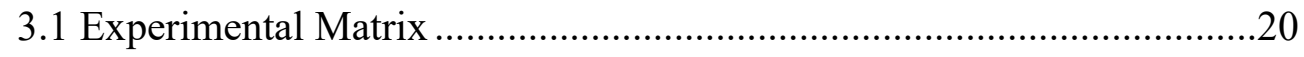

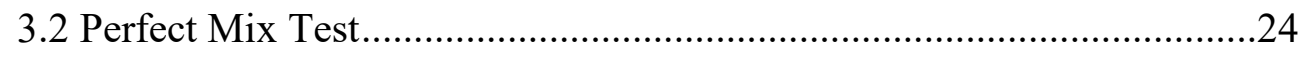

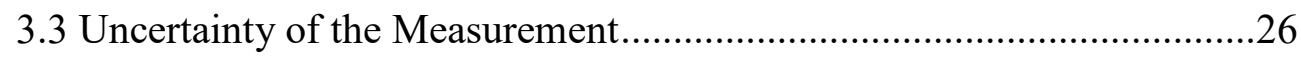

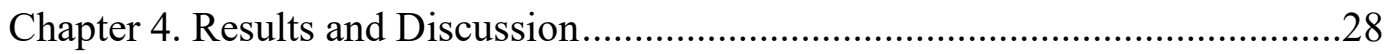

4.1 Diffuser Performance Analysis ............................................................28

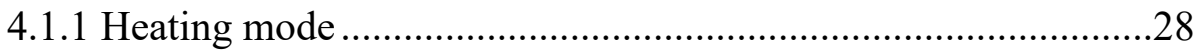

Air change Effectiveness and Temperature Effectiveness..........28

Effects of Internal Load to Air Change Effectiveness and Temperature Effectiveness...................................................31

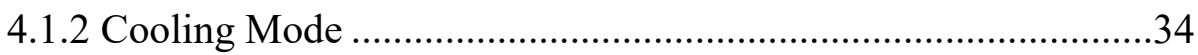

Air Change Effectiveness and Temperature Effectiveness..........34

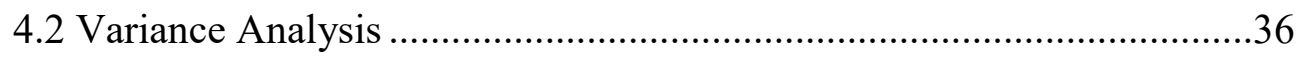

4.2.1 Vertical Variance in the Test Space...............................................37 
4.2.2 Horizontal and Overall Variance in the Test Space.

4.2.3 Correlation of Air Change Effectiveness with Temperature Effectiveness ............................................................................41

4.3 Discussion on the Diffuser Performance Analysis .................................42

4.4 Discussion on Variance of in the Test Space ...........................................45

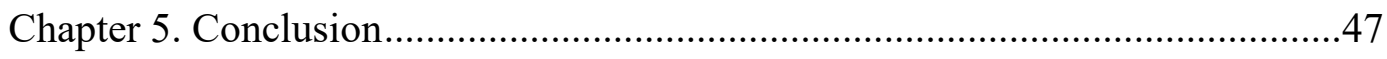

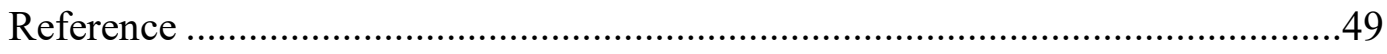

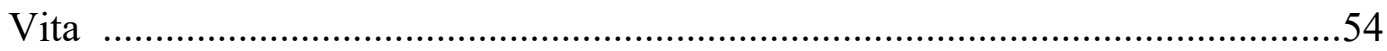




\section{List of Tables}

Table 2.1: Summary of tracer gas method, sampling point and ventilation effectiveness indices specified in standard/guidebook. ....................16

Table 3.1: The experimental matrix (Heating conditions) ...................................23

Table 3.2: The experimental matrix (Cooling conditions/Perfect mix) ..............24

Table 3.3: Perfect mixing test results (control tests introduced to examine

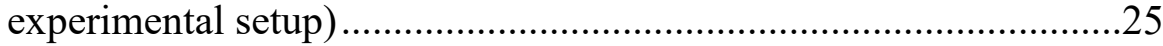

Table 3.4: Uncertainty of air change effectiveness defined by experiments

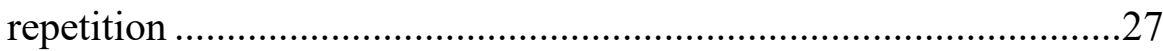

Table 4.1: Horizontal and overall standard deviations of air change effectiveness as

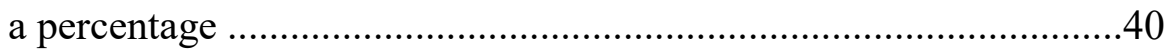

Table 4.2: The range of air change effectiveness, $E$, and temperature effectiveness, $\mathcal{E}_{T}$, within the range of recommended $T_{0.25} / \mathrm{L}$ in terms of $A D P I . \ldots . . . .44$ 


\section{List of Figures}

Figure 2.1: Summary of mixing ventilation studies regarding inlet and outlet configurations (Cao et al. 2013).......................................................

Figure 2.2: Definition of the age of air (Muller et al. 2013) ...............................11

Figure 2.3: Room mean age of air and nominal time constant for different types of airflow (Muller et al. 2013).............................................................12

Figure 3.1: The chamber geometry and sensor positions .....................................22

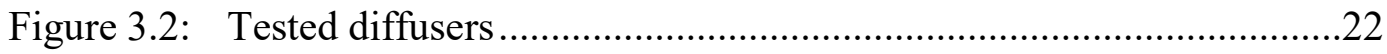

Figure 3.3: Linear slot diffuser adjustment ......................................................24

Figure 4.1: $T_{0.25} / L$ vs. Air change effectiveness, $E$, (left side y-axis) and $A D P I$ from Liu's (2016) experiments (right side y-axis) under heating conditions

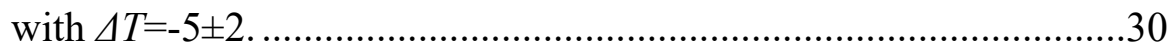

Figure 4.2: $\quad T_{0.25} / L$ vs. temperature effectiveness, $\mathcal{E}_{T}$, under heating conditions with $\Delta T=-5 \pm 2$. 31

Figure 4.3: $T_{0.25} / L$ vs. air change effectiveness, $E$, and temperature effectiveness, $\varepsilon_{T}$, of Linear Slot Diffusers under heating conditions with different $\Delta T$ (Cases 1-9, 16-24 and Cases 10-15, 25-30) .33

Figure 4.4: $\quad T_{0.25} / L$ vs air change effectiveness, $E$, and temperature effectiveness, $\varepsilon_{T}$, of Round Ceiling Diffusers under heating conditions with different $\Delta T$ (Cases 31-37, Cases 38-43 and Cases 44-50) .33

Figure 4.5: $\quad T_{0.25} / L$ vs. air change effectiveness, $E$, (left side y-axis) and ADPI from Liu's (2016) experiments (right side y-axis) under cooling conditions with an internal load of $\Delta T=8 \pm 1$....... 35 
Figure 4.6: $T_{0.25} / L$ vs. temperature effectiveness, $\varepsilon_{T}$, under cooling conditions with an internal load of $\Delta T=8 \pm 1 \ldots$ 36

Figure 4.7: Vertical variances of local air change effectiveness as a percentile. 38

Figure 4.8: Temperature effectiveness, $\varepsilon_{T}$, per experimental settings...............41

Figure 4.9: Correlation between temperature effectiveness, $\varepsilon_{T}$, and overall air change effectiveness, $E$, ...................................................42 


\section{Chapter 1: Introduction}

Providing occupants comfort and healthy environment with the minimum use of energy is the ultimate purpose of heating, ventilating and air conditioning (HVAC) systems. Building ventilation directly affects indoor air quality, and it influences occupants' heath and productivity. Among various types of ventilation, the most known and used ventilation method is mixing ventilation. Mixing ventilation aims to dilute the polluted and cool/warm room air with cleaner and cooler/warmer supply air to lower the contaminant concentration and regulate the temperature. The mixing ventilation method has been applied to large variety of room types through the use of diverse types of air diffusers and exhaust vents. These air distribution devices are used in various HVAC systems such as a variable air flow volume (VAV) systems, which supply air at a constant temperature, and constant air volume (CAV) systems, which vary the temperature of supply air. Furthermore, in most buildings with either VAV or CAV systems, the same mixing ventilation diffusers provide space cooling and heating. The diffusers rarely operate in their design condition, since jet behavior from diffusers may vary in both systems. This is a major challenge for mixing ventilation, as thermal discomfort or low ventilation effectiveness may appear due to varying operation conditions.

Thermal discomfort and impact of draft and temperature non-uniformity is measured with the Air Distribution Performance Index (ADPI). This widely accepted index shows the performance of diffusers when considering spatial temperature and velocity field and is well established in the diffuser selection guideline. ADPI is defined as the percentage of the occupied zone that maintains acceptable velocity and temperature. The region of acceptable velocity and temperature is determined by local 
Effective Draft Temperature (EDT) that combines air temperature difference and air speed (Rydberg and Norback 1949, Straub and Chen 1957, Straub et al. 1956, Koestel and Tuve 1955). ADPI incorporates the throw and the characteristic length, and it provides design variables for selecting diffusers. The current ADPI diffuser selection method is only valid for overhead air distribution systems under cooling operation (Krati et al 2008). However, it is common practice to use the same mixing ventilation diffusers to provide space heating in addition to cooling (Platt et al. 2010, Vakiloraya et al. 2014, Liu et al. 2015). This practice was causing many issues during the heating period. Recently, Liu et al. (2015) expanded the ADPI concept in heating mode and obtained ADPI values with recommended design criteria for various types of diffusers under both cooling and heating mode.

Even this new updated cooling and heating ADPI concept considers only temperature uniformity and drafts caused by high velocity. The impact of stratification and low ventilation effectives with all-air heating systems is taken into account by just one correction factor in the American Society of Heating, Refrigerating, and AirConditioning Engineers (ASHRAE) Standard 62.1 (2010). Combining the ADPI with this correction factor does not always result in the proper diffuser selection that considers both thermal comfort and ventilation effectiveness. For example, when the throw is too short, it is possible that the jet detaches from ceiling and increases draft risk under cooling condition. Also, short throw length may cause inadequate mixing, resulting in high temperature gradient and low air quality under heating condition. It is necessary to have some momentum of flow to obtain an adequate mixing in the occupied zone. However, too large of a supply jet momentum may generate a draft when the flow rate is above a certain level. The temperature difference between return and supply should also be restricted, as a high-temperature difference may cause either a draft and/or a large 
vertical temperature stratification that ends in inefficient energy use. Few studies have focused on ventilation effectiveness with mixing diffusers used for space heating, although all-air-heating ventilation is widely used (Muller et al. 2012). A comprehensive design process for diffuser selection and positioning that considers both thermal comfort and ventilation effectiveness at the same time is needed.

ASHRAE Standard 62.1, the current ventilation design standard, specifies minimum ventilation rate for different type of building. This required ventilation rate is increased or decreased to take into account the impact of ventilation effectiveness. Furthermore ASHRAE Standard 129 (1997) specifies the standard procedure for measuring air change effectiveness. This standard also specifies how to modify the minimum ventilation rate defined in Standard 62.1 to account for differences in air change effectiveness. However, this standard may not be practical for field measurements since it demands extensive measuring equipment or repetitive measurement. Specifically, the standard requires measuring air change effectiveness in $25 \%$ of the workstation or measuring in a minimum of 10 locations throughout the test space. This intensive and costly procedure causes little ability for practical application of ASHRAE Standard 129; as a consequence, air change effectiveness is rarely measured in the field. Since ventilation effectiveness may have significant impacts on both indoor air quality and building energy performance, it is important to define the methods to properly measure it. Therefore, two primary objectives of this study are summarized as flows:

(1) Analyze diffuser performance when considering thermal comfort and ventilation effectives.

Specifically, the goal is to provide supporting data for air distribution system designs for several of the most common types of ceiling diffusers in the cooling and heating regime. A linear slot diffuser, round ceiling diffuser, louvered face diffuser with no lip, and 
perforated diffuser directional pattern (4way) were chosen for testing. This objective should define operation range for selecting diffusers with good ADPI, ventilation effectiveness, and temperature effectiveness.

(2) Study the accuracy of a simple, cost effective method for measuring ventilation effectiveness.

Specifically, this objective assesses the variation of measured air change effectiveness with a reduced number of measuring points. It analyzes the variances of the local air change effectiveness and the correlation of temperature effectiveness with the overall ventilation effectiveness.

This study was experimental and used measurements in a full-scale test room. Carbon dioxide $\left(\mathrm{CO}_{2}\right)$ tracer gas decay tests were conducted to simultaneously measure the age of air at multiple locations in the test room when various types of ceiling diffusers/pattern adjustments, air flow rates and internal loads were implemented. The presented results can be combined with the recently finished project to expand the ADPI based diffuser selection guideline (Liu et al. 2016) by adding an air quality component. 


\section{Chapter 2: Literature Review and Theoretical Background}

This chapter reviews the present studies from relevant literature and introduces the theoretical background of this study. The chapter is divided into four sections. Section 2.1 reviews research on mixing ventilation with an emphasis on overhead supply/return system. Section 2.2 then summarizes the ventilation effectiveness definitions and measurement procedure in different standards. Lastly, Section 2.3 introduces the indices implemented in this study.

\subsection{Mixing Ventilation}

Numerous studies have been conducted on different types of ventilation methods by utilizing various assessment indices. Cao et al. (2013) conducted a comprehensive review of scientific literature on air distribution systems and classified different ventilation systems according to specific requirements and assessment procedures. The ventilation methods are categorized into eight groups: mixing ventilation, displacement ventilation, personalized ventilation, hybrid air distribution, stratum ventilation, protected occupied zone ventilation, local exhaust ventilation, and piston ventilation. In addition, five indices are introduced to assess the ventilation performance: ventilation effectiveness in terms of air exchange, pollutant removal, heat removal, exposure, and the air distribution index. The study shows the assessment of ventilation effectiveness should be identified according to the purpose of the ventilation system and provides the basic framework regarding application of airflow distribution. One of the most comprehensive mixing ventilation guides for mixing ventilation is published by the Federation of European Heating, Ventilation and Air Conditioning Associations (REVHA): REVHA Guidebook No.19 "Guide on mixing air distribution design" (Muller et al. 2013). The 
guidebook gives an overview of the theory of mixing ventilation, design methods and its evaluation with several case studies.

\subsubsection{Influences of Inlet/Outlet Locations}

With mixing ventilation, locations of air inlet and outlet affect air distribution in the space. Cao et al. (2013) summarized the numerous studies of mixing ventilation by comparing different locations of air flow inlets and outlets. Figure 2.1 shows the summary of mixing ventilation studies regarding inlet and outlet configurations (Boyle Son 1899, Clements 1975, Sandberg et al. 1986, Nielsen 1991, Sandberg et al. 1992, Awbi et al. 1993, Lee et al. 2004, Cao et al. 2010, Krajecik et al. 2012).

In addition to Cao's review, Sinha et al. (2000) compared impact of different inlet and outlet locations using models and computational fluid dynamics. The study found that the most effective combination of inlet and outlet positioning is with inlet near the floor and exhaust near the ceiling because the buoyancy force increased the intensity of recirculation with this combination. When considering position of air supplies in the upper part of the room, Lee et al. (2007) experimentally compared high wall jet from grill diffusers with typical ceiling diffusers. Their results show that the air inlet position and type are important determinants in the distribution of airborne contaminant concentrations. Overall, the ceiling diffuser produced more efficient ventilation than the wall jet air inlet. Unlike the air supply location, impact of the air exhaust location to structure of room air flow is marginal in most cases (Muller et al. 2013). This is because there is a rapid decay of velocity with increasing distance from exhaust opening. However, the exhaust location may influence air change effectiveness and contaminant removal effectiveness. In Khan's study (2006), the arrangements of wall inlet and outlet 
greatly influence contaminant concentration. However, the influence of the outlet location is minimal with ceiling diffuser inlet.

\begin{tabular}{|c|c|c|c|c|}
\hline & Locations of a irflow inlet and outlet & Methods & Main focus & Findings \\
\hline $\begin{array}{l}\text { Boyle Son } \\
\qquad(1899)[19]\end{array}$ & Inlet & Investigation & $\begin{array}{l}\text { Airflow distribution and } \\
\text { indoor air qual ity. }\end{array}$ & $\begin{array}{l}\text { - This is one of the very earliest forms of } \\
\text { mechanical vent ilation } \\
\text { - Downdraught ventilation by mechanical } \\
\text { impulsion is pronounced by public health } \\
\text { experts to be highly prejudicial to health. }\end{array}$ \\
\hline $\begin{array}{l}\text { Clements } \\
\text { (1975) [14] }\end{array}$ & $\rightarrow$ Inlet & $\begin{array}{l}\text { Model } \\
\text { experiment }\end{array}$ & $\begin{array}{l}\text { Airflow partern and the } \\
\text { effect of Archimedes } \\
\text { number. }\end{array}$ & $\begin{array}{l}\text { - The air partem is almost a function of the } \\
\text { Archimedes number. As Ar increases, the } \\
\text { jet deflection from the horizontal increases }\end{array}$ \\
\hline $\begin{array}{l}\text { Sandberg et al. } \\
\text { (1986) [25] }\end{array}$ & $\begin{array}{ll}\text { Inlet } & \text { Outlet } \\
\text { Inlet }\end{array}$ & $\begin{array}{l}\text { Experimental } \\
\text { study }\end{array}$ & $\begin{array}{l}\text { Air exchange efficiency } \\
\text { and contaminant } \\
\text { exposure. }\end{array}$ & $\begin{array}{l}\text { - The ceiling-to-floor system gives rise to } \\
\text { a comparatively rapid exchange of the } \\
\text { air with heating However, the evacuation } \\
\text { of the contaminant is delayed. }\end{array}$ \\
\hline $\begin{array}{l}\text { Nieksen } \\
\quad(1991)[111]\end{array}$ & Inlet Outlet & $\begin{array}{l}\text { Modeling and } \\
\text { experimental } \\
\text { study }\end{array}$ & $\begin{array}{l}\text { Simplified design } \\
\text { method. }\end{array}$ & $\begin{array}{l}\text { - Simplified design models work well with } \\
\text { simple geometry } \\
\text { - Measurements show significant deviation. }\end{array}$ \\
\hline $\begin{array}{l}\text { Sandberg et al. } \\
\text { (1992) [26] }\end{array}$ & $\begin{array}{l}\text { Attached } \\
\text { plane jet }\end{array}$ & $\begin{array}{l}\text { Experimental } \\
\text { study }\end{array}$ & $\begin{array}{l}\text { The eflect of Ardhimedes } \\
\text { number on the airflow } \\
\text { distribution. }\end{array}$ & $\begin{array}{l}\text { - The critical supply Archimedes number } \\
\text { at which the jet breaks away from the } \\
\text { surface as soon as it leaves the nozzle } \\
\text { was just below } 0.03 \text {. }\end{array}$ \\
\hline $\begin{array}{r}\text { Awti and Gan } \\
\text { (1993) [27] }\end{array}$ & $\rightarrow$ Inlet & Numerical study & $\begin{array}{l}\text { Air distribution and } \\
\text { ventilation eflectiveness }\end{array}$ & $\begin{array}{l}\text { - Air distribution systems should be } \\
\text { different for heating and cooling in } \\
\text { order to achieve a comfortable room } \\
\text { environment. }\end{array}$ \\
\hline $\begin{array}{l}\text { Lee and Awbi } \\
\text { (2004) [28] }\end{array}$ & $\begin{array}{cc}V \\
\text { Inlet }\end{array}$ & $\begin{array}{l}\text { Experimental and } \\
\text { numerical study }\end{array}$ & $\begin{array}{l}\text { The effects of partitions } \\
\text { on the room air quality } \\
\text { as well as ventilation } \\
\text { performance. }\end{array}$ & $\begin{array}{l}\text { - Increasing the partition gap underneath } \\
\text { from 0:H to } 108 \mathrm{~g} \text { causes an overall } \\
\text { improvement in the air change efficiency. }\end{array}$ \\
\hline $\begin{array}{l}\text { Cas et al } \\
\quad(2010)[29]\end{array}$ & Inlet & Experimental study & $\begin{array}{l}\text { Maximum velodty decay } \\
\text { in the air distribution } \\
\text { via attached plane jet. }\end{array}$ & $\begin{array}{l}\text { - Attached plane jet can be used as an } \\
\text { effective method to avoid dra ught in } \\
\text { mixing ventilation conditions }\end{array}$ \\
\hline $\begin{array}{l}\text { Krajack et al } \\
\text { (2012) [33] }\end{array}$ & $\begin{array}{ll}\rightarrow \text { Inlet } & V \\
\text {-Outlet } & \text { Outlet }\end{array}$ & $\begin{array}{l}\text { Experimental } \\
\text { study }\end{array}$ & $\begin{array}{l}\text { Air distribution and } \\
\text { ventilation effectiveness }\end{array}$ & $\begin{array}{l}\text { - The ventilation effectiveness varied } \\
\text { between } 0.4 \text { and } 1.2 \text { where } 1 \text { is } \\
\text { complete mixing which depends on } \\
\text { the position of air terminal devies }\end{array}$ \\
\hline
\end{tabular}

Figure 2.1: Summary of mixing ventilation studies regarding inlet and outlet configurations (Cao et al. 2013). 


\subsubsection{Influences of Space Objects}

Space partitioning such as cubicles and internal objects such as furniture or occupants may also affect effectives of the air distribution (Shaw et al. 1993, Lee et al. 2004, Wu et al. 2015). However, Shaw et al. (1993) showed the presence of cubicles (with partition height of $1.9 \mathrm{~m}$ in a space with total height of $2.9 \mathrm{~m}$ ) had no significant effects on the air distribution patterns. They also found that the layout of a cubicle on the ventilation efficiency is very small. The study of the impact of the cubicle height by Lee (2004) shows that internal partition up to $60 \%$ of room height has very small impact on

the air distribution, while an internal partition of $80 \%$ of room height significantly impacts the room air flow. When considering occupants, Wu et al. (2015) conducted a test on walking humans in a test chamber and analyzed impact on $\mathrm{CO}_{2}$ concentration and temperature distributions in the space with three different ventilation method (stratum, displacement, and mixing ventilation). The study showed that short term walking did not change the temperature or $\mathrm{CO}_{2}$ concentration profiles. However, mixing occurred when occupants walked over a longer period of time.

From the Section 2.1.1 and 2.1.2, it is considered that the air supply diffusers, namely the location and type of air supply openings, is the dominant factor that characterizes the air distribution in mixing ventilation with an overhead supply/return configuration.

\subsubsection{Ventilation Effectiveness under Heating Mode}

The aforementioned studies show that many factors influence the supply air distribution with mixing ventilation systems emphasis on cooling mode. In this application the overall effectiveness of the air distribution is slightly better or worse than the one with perfect mixing. However, fewer studies focused on ventilation effectiveness 
with mixing diffusers used for space heating. Air distribution with all-air-heating is one of the major challenges for mixing air distribution. Although, all-air-heating ventilation is widely used, researchers found low ventilation effectiveness under heating condition (Fisk et al. 1997, Offermann et al. 1989, Krajcik et al. 2012, Tomasi et al. 2013, Novoselac et al. 2003). Fisk et al. (1997) conducted experiments that used overhead allair-heating system that supplied minimum air supply flow rate of typical VAV systems. The air change effectiveness was significantly lower than 1.0 in each experiment. The measured air change effectiveness was in the range of 0.69-0.91 with mean value of 0.81 . Offermann et al. (1989) measured ventilation effectiveness and ADPI under heating conditions with recommended minimum ventilation rate while considering different supply and return positions. For the ceiling supply/return configuration, ventilation effectiveness was 0.73 when temperature difference of supply air temperature and room average temperature was $8{ }^{\circ} \mathrm{C}$. This value was even lower, 0.66 , when the difference was $13^{\circ} \mathrm{C}$. Short-circuit flow from the supply to exhaust was apparent for each configuration. This low ventilation effectiveness under the heating condition was implemented into the ASHRAE standard 62.1 (2010) which defines zone air distribution effectiveness of 1.0 when the ceiling supply of warm air is less than $8{ }^{\circ} \mathrm{C}$ above space temperature and the supply air jet throw with velocity of $0.8 \mathrm{~m} / \mathrm{s}, T_{0.8}$, reaches lower part of the room (area that is $1.4 \mathrm{~m}$ above the floor level). When this $0.8 \mathrm{~m} / \mathrm{s}$ jet throw does not reach the lower part of the room or when the supply-room temperature difference is larger than $8{ }^{\circ} \mathrm{C}$, the nominal ventilation effectiveness is 0.8 . 


\subsection{Ventilation Effectiveness in Standards}

Three different standards or guidebooks regarding ventilation effectiveness are reviewed in this section. The publications include ASHRAE Standard 129 (1997) “Measuring Air-Change Effectiveness", REVHA Guidebook No.2 (Muller et al. 2013) "Ventilation Effectiveness", and the Society of Heating, Air-Conditioning and Sanitary Engineers of Japan (SHASE) Standard 116 (2001) "Field Measurement Methods for Ventilation Effectiveness in Rooms". All three organizations introduce the age of air concept based on tracer gas measurement. Figure 2.1 shows the concept of the age of air. The age of air (Sandberg 1981) is defined as the average time elapsed since molecules of air in a given volume of air entered the building from outside. The air at point $P$ is a mixture of components of different air spent different time in the room. The local mean age of air, $\bar{\tau}_{\rho}$, measures the quality of air at a given point. In the exhaust air stream, the local mean age of air is equal to the nominal time constant, $\tau_{n}$,

$$
\tau_{n}=\frac{V}{q_{v}}
$$

in which $V$ is the room air volume and $q_{v}$ is the ventilation flow rate. When there is more than one exhaust outlet, the nominal time constant is also defined as weighted average of local mean age of air in exhaust air stream:

$$
\tau_{n}=\frac{\sum_{m}\left(Q_{e x, m} \bar{\tau}_{e x, m}\right)}{\sum_{m} Q_{e x, m}}
$$


in which $m$ is an identification number unique for each exhaust air stream, $Q_{e x, m}$, is the rate of airflow in exhaust airstream $m$, and $\bar{\tau}_{e x, m}$ is the age of air in exhaust air stream $m$. The room mean age of air, $\langle\bar{\tau}\rangle$, is equal to the spatial average of the local mean ages of air, $\left\langle\bar{\tau}_{p}\right\rangle$. Figure 2.3 shows the room mean age of air, $\langle\bar{\tau}\rangle$, and the nominal time constant, $\tau_{n}$, for four different types of airflow. In an ideal piston flow, the average room age of air, $\langle\bar{\tau}\rangle$, is $\tau_{n} / 2$, and $\langle\bar{\tau}\rangle$ is equal to $\tau_{n}$ in fully mixed airflow. If there is a shortcircuit flow from the supply to the exhaust, the local mean age of air will be low in the short-circuited zone and high in the stagnant zone. The air change time for all the air in the room, $\bar{\tau}_{r}$, is equal to twice the room mean age of air, $\langle\bar{\tau}\rangle$.

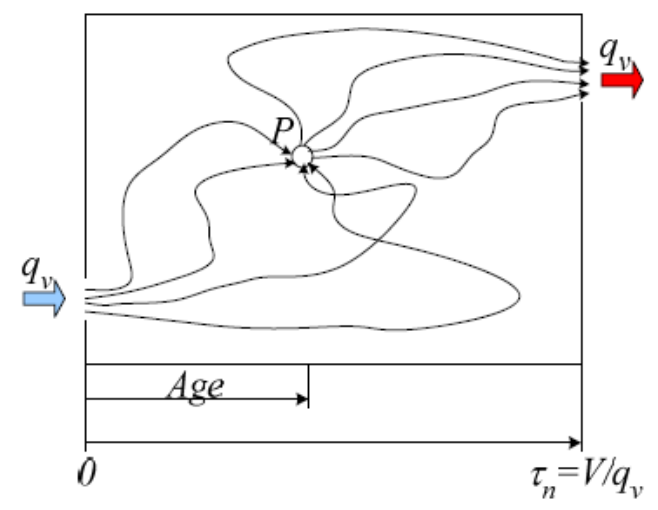

Figure 2.2: Definition of the age of air (Muller et al. 2013) 

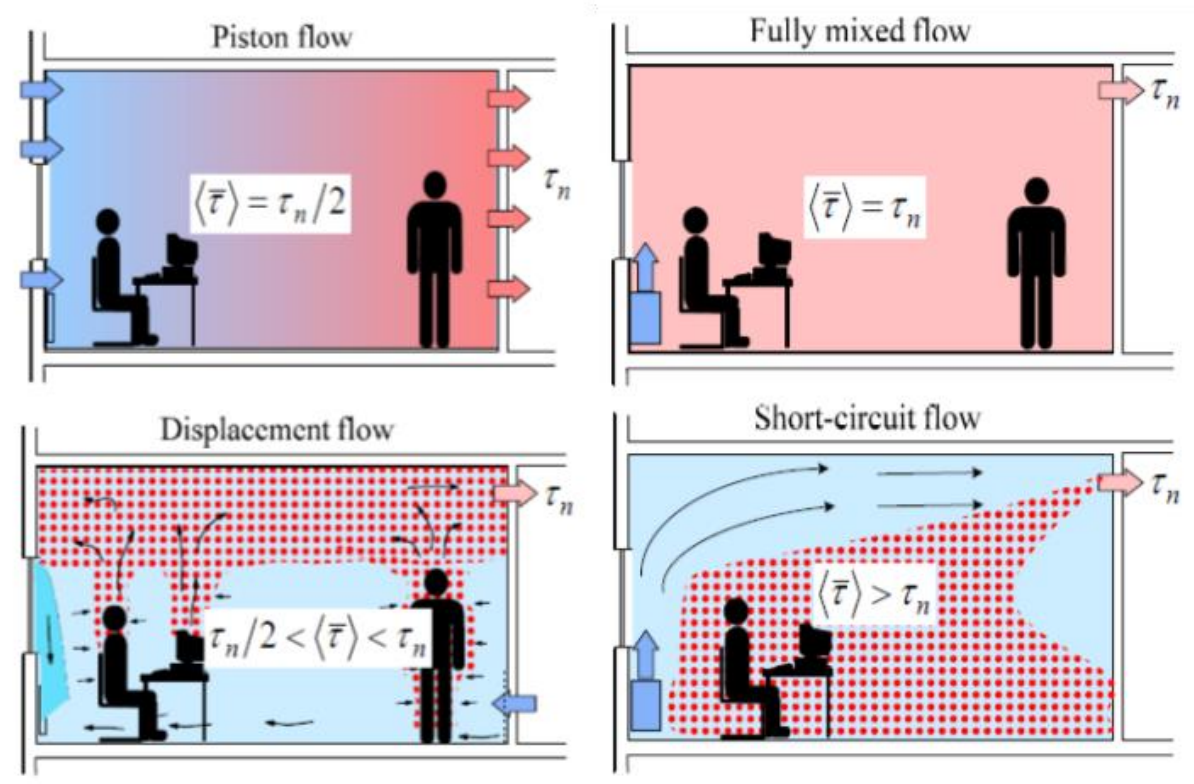

Figure 2.3: Room mean age of air and nominal time constant for different types of airflow (Muller et al. 2013)

The age of air is measured by measuring tracer gas concentration, which labels the indoor air with inert or nonreactive gas (Dietz et al. 1986, Fisk et al. 1989, Fortmann et al. 1990; Harrje et al. 1990, Lagus and Persily 1985, Persily 1988, Persily and Axley 1990, Sherman 1989, 1990, Sherman et al. 1980). The tracer step-down (decay) method and tracer step-up method are the most common techniques to evaluate the age of air. In a decay test, concentration of tracer gas at the start of the measurement is assumed uniform. The tracer gas concentration in the space then decreases at a rate that depends on the airchange rate. From the decay test, the age of air at a point $p$ in the space, $\bar{\tau}_{p}$, is given by the following equation.

$$
\bar{\tau}_{p}=\frac{1}{C_{0}} \int_{0}^{\infty} C_{p}(t) d t
$$


in which $C_{0}$ is the concentration of tracer gas at a time $\mathrm{t}=0$ and $C(t)$ is the concentration decay recorded at each point.

In a tracer step-up measurement, the tracer gas concentration is assumed to equal at the beginning of the measurement. Tracer gas is injected into the outdoor air being delivered to the space at a constant rate. Tracer gas concentration increases to an equilibrium value $C$ at a rate that depends on the air-change rate. The local age of air at a point $p$ in the space, $\bar{\tau}_{p}$, is given by the following equation.

$$
\bar{\tau}_{p}=\int_{0}^{\infty}\left(1-\frac{C_{p}(t)}{C_{\infty}(t)}\right) d t
$$

Although the same age of air concept is implemented in three different publications, ventilation effectiveness indices are slightly different. In addition, recommended measurement methods and sampling points also vary. Table 2.1 summarizes the ventilation effectiveness indices, method and sampling point in each publication. The ASHRAE standard only refers tracer gas step down and step down method as tracer gas technique, while the REVHA guidebook and SHASE standard introduce a pulse method in addition. ASHRAE introduces other tracer gas technique such as constant concentration/injection method (Fortmann et al. 1990, Walker and Forest 1995, Walker and Wilson 1998) in the Handbook (2009). The ASHRAE standard also requires evaluation of the local age of air at $25 \%$ of workstations but not at less than ten workstations. On the other hand, the SHASE standard requires measurement at a minimum of three points or three repetitive measurements with one point in the target space. The measuring point should be near the center of each span (between columns) or each $10 \mathrm{~m}$ by $10 \mathrm{~m}$ grid. 
Regarding the ventilation effectiveness indices, ASHRAE standard defines the Air Change Effectiveness, E. From the local mean age of air, $\bar{\tau}_{\rho}$, the air change effectiveness of the test space, $E$, is defined as

$$
E=\frac{\tau_{n}}{\left\langle\bar{\tau}_{v}\right\rangle}
$$

in which $\left\langle\bar{\tau}_{v}\right\rangle$ is the arithmetic average of the age of air measured at breathing level within the test space. Value of $E$ less than 1.0 indicates a degree of stagnation, while values of $E$ greater than 1.0 suggest a degree of plug or displacement flow are present (Rock 1992). Similar to the air change effectiveness $E$ in ASHRAE standard, SHASE standard defines the standardized occupied zone concentration, $C_{n}$. The standardized occupied zone concentration, $C_{n}$, is defined as inverse of air change effectiveness, $E$, in ASHRAE standard.

$$
C_{n}=\frac{\left\langle\tau_{v}\right\rangle}{\tau_{n}}
$$

In REVHA guidebook, the air change efficiency, $\varepsilon^{a}$, is implemented. Air change efficiency is defined as the ratio between the shortest possible air change time for the air in the room (the nominal time constant, $\tau_{n}$ ) and the actual air change time, $\tau_{r}$. The definition of the air change efficiency can also be explained as the ratio between the lowest possible mean age of air, $\tau_{n} / 2$, and the room mean age of air, $\langle\bar{\tau}\rangle$.

$$
\varepsilon^{a}=\frac{\tau_{n}}{\bar{\tau}_{r}} \cdot 100=\frac{\tau_{n}}{2\langle\bar{\tau}\rangle} \cdot 100 \quad[\%]
$$


The upper limit for this efficiency is $100 \%$, which occurs for ideal piston flow. It is worth noting that the air change efficiency is defined using the room mean age of air, while the air change effectiveness and standardized occupied zone concentration is defined with the mean age of air at breathing level. The REVHA guidebook also specifies the index that shows the conditions at a particular point. The local air change index is defined as the ratio of the nominal time constant and the local mean age of air. The local air change index, $\varepsilon_{p}^{a}$, is described as

$$
\varepsilon_{p}^{a}=\frac{\tau_{n}}{\tau_{p}} \cdot 100 \quad[\%]
$$

The local mean age of air is the same in the whole room in perfect mixing and equal to the nominal time constant and local air change index is equal to $100 \%$. 


\begin{tabular}{|c|c|c|c|}
\hline & $\begin{array}{c}\text { ASHRAE } \\
\text { Standard } 129\end{array}$ & $\begin{array}{c}\text { REVHA } \\
\text { Guidebook No.2 }\end{array}$ & $\begin{array}{c}\text { SHASE } \\
\text { Standard } 115\end{array}$ \\
\hline Indices & -Air Change Effectiveness & $\begin{array}{l}\text {-Air Change Efficiency } \\
\text {-Local Air Change Index } \\
\text {-Contaminant Removal } \\
\text { Effectiveness } \\
\text {-Local Air Quality Index }\end{array}$ & $\begin{array}{l}\text {-Standardized Occupied } \\
\text { Zone Concentration }\end{array}$ \\
\hline $\begin{array}{l}\text { Tracer gas } \\
\text { Methods }\end{array}$ & $\begin{array}{l}\text {-Tracer Gas Step-up } \\
\text {-Tracer Gas Step-down }\end{array}$ & $\begin{array}{l}\text {-Tracer Gas Step-up } \\
\text {-Tracer Gas Step-down } \\
\text {-Pulse } \\
\text {-Homogeneous constant } \\
\text { emission method }\end{array}$ & $\begin{array}{l}\text {-Tracer Gas Step-up } \\
\text {-Tracer Gas Step-down } \\
\text {-Pulse }\end{array}$ \\
\hline $\begin{array}{l}\text { Sampling } \\
\text { points }\end{array}$ & $\begin{array}{l}-25 \% \text { of workstations but } \\
\text { not at less than ten } \\
\text { workstations nor at less than } \\
\text { the total work stations if the } \\
\text { test space contains fewer } \\
\text { than ten }\end{array}$ & $\begin{array}{l}\text {-one or more places in the } \\
\text { room or in exhaust air }\end{array}$ & $\begin{array}{l}\text {-near the center of span } \\
\text { (between columns) by span } \\
\text { or } 10 \mathrm{~m} \text { by } 10 \mathrm{~m} \text {, minimum } \\
3 \text { points in the target space }\end{array}$ \\
\hline $\begin{array}{l}\text { Ventilation } \\
\text { effectiveness } \\
\text { Indices }\end{array}$ & -Air Change Effectiveness & $\begin{array}{l}\text {-Air Change Efficiency } \\
\text {-Local Air Change Index } \\
\text {-Contaminant Removal } \\
\text { Effectiveness } \\
\text {-Local Air Quality Index }\end{array}$ & $\begin{array}{l}\text {-Standardized Occupied } \\
\text { Zone Concentration }\end{array}$ \\
\hline
\end{tabular}

Table 2.1: Summary of tracer gas method, sampling point and ventilation effectiveness indices specified in standard or guidebook.

\subsection{Indices Implemented in this Study}

This section explains the theoretical background and indexes implemented in this study. Among several indices, $T_{0.25} / L$ and $A D P I$, air change effectiveness, and temperature effectiveness were utilized to evaluate the performance of the diffusers regarding thermal comfort, ventilation effectiveness, and heat removal efficiency. The chosen indices are well researched and widely used in the industry and by many researchers. 


\subsection{1 $T_{0.25} / L$ and $A D P I$}

Diffuser selection, location, supply air volume, discharge velocity, and air temperature differential result in air motion in the occupied zone. Three methods are commonly used when selecting the diffusers in mixing ventilation: (1) by appearance, flow rate, and sound data, (2) by isovels (lines of constant velocity) and mapping and (3) by comfort criteria (ASHRAE Handbook 2009). The last method, comfort criteria, involves $T_{0.25} / L$. This utilizes manufactures' isothermal catalogue throw data at $0.25 \mathrm{~m} / \mathrm{s}$ terminal velocity $\left(T_{0.25}\right)$ and the dimensions available for the throw $(L)$ on the diffusers. $T_{0.25} / L$ is a dimensionless index that categorizes the performance of diffusers in the targeted space. Calculating $T_{0.25} / L$ can predict ADPI which indicates comfort level of occupants in the space. Designers may select and locate diffusers from the rage of $T_{0.25} / L$ that can achieve $A D P I$ higher than 80. (Miller and Nevins 1969, 1970, 1972, Miller 1971, 1979, Miller and Nash 1971). Recommended $T_{0.25} / L$ values to achieve acceptable $A D P I$ values are unique with each diffuser. In this study, $T_{0.25} / L$ is used as an index that characterizes diffuser types and air flow rates in both under cooling and heating conditions. Recommended $T_{0.25} / \mathrm{L}$ for each diffuser in terms of achieving acceptable ADPI were referred from Liu's study (2016).

\subsubsection{Air Change Effectiveness}

As explained in Section 2.2, several indices of ventilation effectiveness have been proposed by different organizations and researchers. Among other indices, the age of air approach to the air change effectiveness defined in the ASHRAE standard 129 will be implemented in this research. The air change effectiveness is 1.0 when the air from the diffuser is perfectly mixed in the space. From equation (2.2), the nominal time constant, $\tau_{n}$, is equal to the age of air in exhaust air steam, $A$, because a single exhaust was used in 
the experiments. In addition, $A_{E}$ of each case was computed from the correlation of exhaust air volume in the HVAC control system, and the actual air flow rate was computed from the age of air in exhaust air stream, which was obtained from a pre-test. The arithmetic mean of $E_{i}$ in low measuring plane, high measuring plane and overall test space are referred as $E_{\text {low }}, E_{\text {high }}$ and $E$, respectively. $E$ is defined as air change effectiveness of the space in each case.

\subsubsection{Temperature Effectiveness}

Introducing warm air to the test space may result thermal stratification under the ceiling due to a short circuit air flow pattern above occupied zone caused by the buoyancy effect. Liu's study (2015) implies that warm air from diffusers with small $T_{0.25} / L$ causes a greater temperature gradient in the upper region. Ventilation effectiveness might be low with such high thermal stratification, although the calculated ADPI is as high as 95\%. Temperature effectiveness (Etheridge et al. 1996), also defined as ventilation effectiveness for heat removal (Awbi et al. 1993), was implemented to evaluate the temperature gradient in the test space. Similar to the concept of the local air change effectiveness, $E_{i}$, the temperature effectiveness, $\varepsilon_{T}$, is defined as

$$
\varepsilon_{T}=\frac{T_{S}-T_{E}}{T_{S}-\langle T\rangle_{O}} \times 100 \quad[\%]
$$

in which $T_{S}$ is the supply air temperature, $T_{E}$ is the exhaust air temperature and $\left\langle T>_{0}\right.$ is the average temperature in occupied space. In this experiment, average values of $T_{0.1}$, 
$T_{0.6}, T_{1.1}, T_{1.4}$ and $T_{1.8}$ were used, where the index shows vertical distance of the sensor form the floor in meter. 


\section{Chapter 3: Methodology}

This chapter describes the experimental setup and the methods used in the experiments. The chapter is divided into three sections. Section 3.1 summarizes the experimental matrix and diffusers tested in the experiments. Section 3.2 then examines the results of the perfect mix tests to confirm the validity of the experiments. Lastly, Section 3.3 discusses the uncertainty of the measurement from repetitive tests.

\subsection{Experimental Matrix}

The study used experimental measurements in a full-scale test room with dimensions of $5.5 \mathrm{~m} \times 4.5 \mathrm{~m} \times 2.7 \mathrm{~m}$ and a sophisticated HVAC control system. Figure 3.1 shows the chamber geometry and sensor positions. The experimental setup allowed different diffuser mounting positions: ceiling position for ceiling diffusers (round ceiling, louvered face and perforated diffusers) and linear slot diffusers. Cooled panels with the total area of $10.8 \mathrm{~m}^{2}$ were covering one of the room walls, simulating a cold window surface in winter. The panels were connected to the dedicated chiller system, and the temperature of the panels was adjusted for simulating various heating loads. To simulate cooling load, when the diffuser supplied cooled air, adjustable electric heaters were installed throughout the test room to mimic the cooling load of occupants, computers, lighting fixtures and floor heat patches caused by transmitted solar radiation. More information about the chamber can be found in Liu's study (2014). $\mathrm{CO}_{2}$ was used as a tracer gas for the decay test. The concentration decays were measured by in-situ $\mathrm{CO}_{2}$ sensors (TELAIR model 7001, Accuracy: $\pm 50 \mathrm{ppm}$ or 5\%) at 18 locations in the occupied zone of the room. Measurement at all 18 locations was simultaneous, and the sensors were positioned across the room at two different horizontal planes, $0.9 \mathrm{~m}$ (low measuring 
plane) and $1.5 \mathrm{~m}$ (high measuring plane), above the floor (Figure 3.1). In addition, vertical temperature distributions were measured to identify temperature stratification.

Table 3.1 and Table 3.2 display the experimental conditions. Experiments were conducted under heating and cooling conditions with four different diffusers, $T_{0.25} / L$ (Air change rate) and internal loads. Each set of experiments had subsets of various $T_{0.25} / L$ values. For example, a set of Cases 1-9 had subsets of $T_{0.25} / L$ as 1.2 (Case 1$), T_{0.25} / L$ as 1.6 (Case 2), $T_{0.25} / L$ as 1.8 (Case 3), and so on. Air change rate are also shown in parenthesis for reference. Overall, 118 experiments were conducted: 82 cases for heating, 26 cases for cooling. Internal loads, $\Delta T$, indicate differences between supply air temperature, $T_{S A}$, and exhaust air temperature, $T_{E A}$. The cooled panels temperature and electric heaters were controlled to achieve targeted internal loads, $\Delta T$. The electric heaters were off at heating conditions, and the cooled panels were off at cooling conditions. Figure 3.2 shows the four different tested diffusers; linear slot diffuser (Price), round ceiling diffuser (Metal), louvered face diffuser with no lip (Metal) and perforated diffuser directional pattern (4way) (Titus).

Linear slot diffusers and perforated diffuser directional pattern (4way) provide various airflow patterns by adjusting deflectors. However, those deflectors were adjusted to blowout horizontally. As shown in Figure 3.3 leakage was sealed for linear slot diffuser, to prevent the air bypass through half of the slot and achieve ideal flow pattern (Liu et al. 2016). 

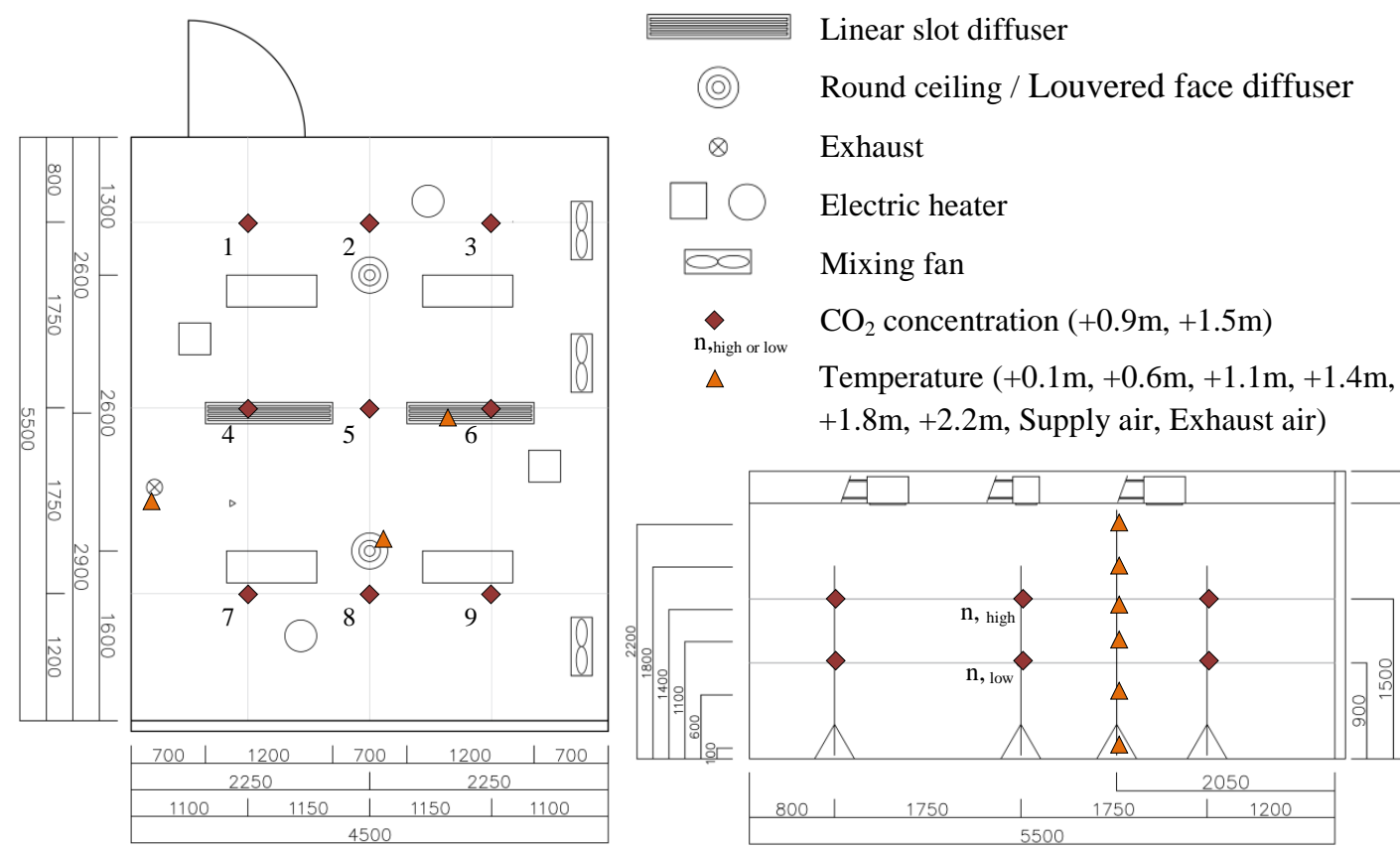

Figure 3.1: The chamber geometry and sensor positions

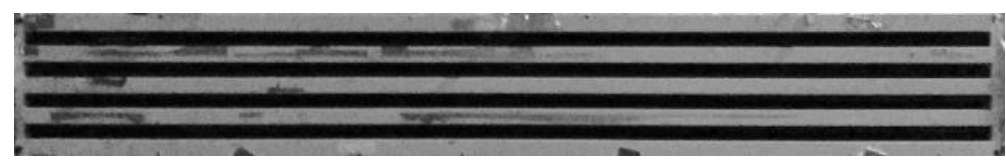

a-1) Linear Slot Diffuser (120cm long, slot width $1.9 \mathrm{~cm}$ )

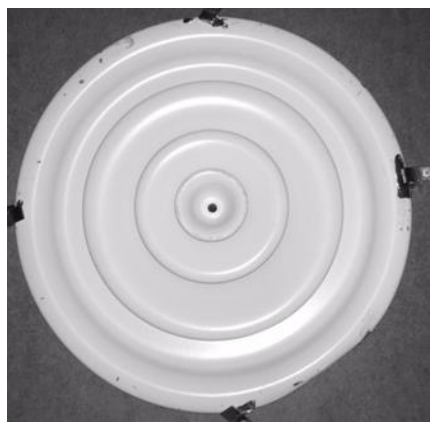

b) Round Ceiling Diffuser $\left(15 \mathrm{~cm}^{*}\right)$

*size in duct diameter

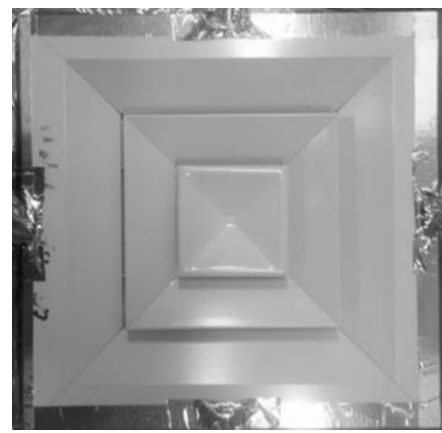

c) Louvered Face Diffuser with no lip $\left(15 \mathrm{~cm}^{*}\right)$

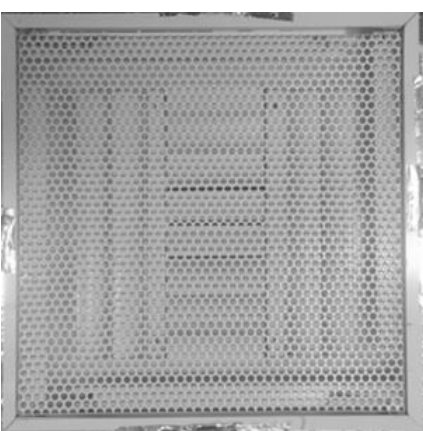

d) Perforated diffuser directional pattern (4way) $\left(15 \mathrm{~cm}^{*}\right)$

Figure 3.2: Tested diffusers 


\begin{tabular}{|c|c|c|c|}
\hline Cases \# & Diffusers & $\begin{array}{l}\mathrm{T}_{0.25} / \mathrm{L}[-] \\
\left.\text { (Air change rate }\left[\mathrm{h}^{-1}\right]\right)\end{array}$ & $\begin{array}{c}\text { Internal load } \\
\left(\Delta T=T_{E A}-T_{S A}\right) \\
{\left[{ }^{\circ} \mathrm{C}\right]}\end{array}$ \\
\hline \multicolumn{4}{|c|}{ Heating Conditions } \\
\hline $1-9$ & $\begin{array}{l}\text { Linear Slot Diffuser } \\
\text { (2slots) }\end{array}$ & $\begin{array}{l}1.2(1.1), 1.6(2.1), 1.8(3.0) \\
1.9(3.3), 2.3(4.5), 2.6(5.8) \\
2.9(6.9), 2.9(7.2), 3.2(8.6)\end{array}$ & $-5 \pm 2$ \\
\hline $10-15$ & $\begin{array}{l}\text { Linear Slot Diffuser } \\
\text { (2slots) }\end{array}$ & $\begin{array}{l}1.6(2.1), 2.0(3.3), 2.6(5.7) \\
2.6(5.8), 2.9(7.2), 3.2(8.6)\end{array}$ & $-2 \pm 2$ \\
\hline $16-24$ & $\begin{array}{l}\text { Linear Slot Diffuser } \\
\text { (4slots) }\end{array}$ & $\begin{array}{l}\mathbf{0 . 9 ( 2 . 1 ) , 0 . 9 ( 2 . 1 ) ,} 1.1(2.7) \\
1.4(3.2), 1.9(4.5), 2.2(5.8) \\
2.5(6.9), 2.5(7.2), 2.7(8.7)\end{array}$ & $-5 \pm 2$ \\
\hline $25-30$ & $\begin{array}{l}\text { Linear Slot Diffuser } \\
\text { (4slots) }\end{array}$ & $\begin{array}{l}0.9(2.1), 1.4(3.3), 1.9(4.5) \\
2.2(5.8), 2.5(7.2), 2.7 \\
(8.6) 2.1,3.3,4.5,5.8,7.2 \\
8.6\end{array}$ & $-2 \pm 2$ \\
\hline $31-37$ & Round Ceiling Diffuser & $\begin{array}{l}0.7(2.1), 1.0(3.3), 1.2(4.5) \\
1.4(5.8), 1.7(7.2), 2.0(8.6) \\
2.0(8.6)\end{array}$ & $-8 \pm 2$ \\
\hline $38-43$ & Round Ceiling Diffuser & $\begin{array}{l}0.7(2.1), 1.0(3.8), 1.2(4.6) \\
1.4(5.8), 1.7(7.2), 2.0(8.6)\end{array}$ & $-5 \pm 2$ \\
\hline $44-50$ & Round Ceiling Diffuser & $\begin{array}{l}0.7(2.1), 0.7(2.2), 0.9(3.3) \\
1.2(4.4), 1.4(5.7), 1.7(7.2) \\
2.0(8.6)\end{array}$ & $-2 \pm 2$ \\
\hline $51-56$ & $\begin{array}{l}\text { Louvered Face Diffuser } \\
\text { with no lip }\end{array}$ & $\begin{array}{l}1.8(3.0), 2.0(3.9), 2.1(4.2) \\
\underline{\mathbf{2 . 6}(\mathbf{6 . 3}), \mathbf{2 . 6}(\mathbf{6 . 3}), 3.5(9.4)}\end{array}$ & $-5 \pm 2$ \\
\hline $57-62$ & $\begin{array}{l}\text { Perforated Diffusers } \\
\text { Directional Pattern (4way) }\end{array}$ & $\begin{array}{l}0.8(2.1), 1.4(3.3), 1.8(4.5) \\
2.2(5.8), 2.4(7.2), 2.7(8.6)\end{array}$ & $-5 \pm 2$ \\
\hline $63-72$ & $\begin{array}{l}\text { Linear Slot Diffuser (2slots) } \\
\text { (Vertical flow) }\end{array}$ & $\begin{array}{l}\text { (2.1), (2.1), (3.0), (3.3), (4.4), } \\
(\mathbf{4 . 4 )}, 5.8,6.9,7.2,8.6\end{array}$ & $-4 \pm 2$ \\
\hline $73-82$ & $\begin{array}{l}\text { Linear Slot Diffuser (4slots) } \\
\text { (Vertical flow) }\end{array}$ & $\begin{array}{l}\frac{(2.1),(2.1)}{(4.5),(5.8),(6.9),(3.3),(4.4),}, \\
(7.2),(8.6)\end{array}$ & $-4 \pm 2$ \\
\hline
\end{tabular}

Cases with underline: repeated experiments

Table 3.1: The experimental matrix (Heating conditions) 


\begin{tabular}{|c|c|c|c|}
\hline Cases \# & Diffusers & $\begin{array}{l}\mathrm{T}_{0.25} / \mathrm{L}[-] \\
\left.\text { (Air change rate }\left[\mathrm{h}^{-1}\right]\right)\end{array}$ & $\begin{array}{c}\text { Internal load } \\
\left(\Delta T=T_{E A}-T_{S A}\right) \\
{\left[{ }^{\circ} \mathrm{C}\right]}\end{array}$ \\
\hline \multicolumn{4}{|c|}{ Cooling Conditions } \\
\hline $83-87$ & Linear Slot Diffuser (2slots) & $\begin{array}{l}1.6(2.1), 1.9(3.3), 2.3(4.5) \\
2.6(5.8), 3.2(8.6)\end{array}$ & $8 \pm 1$ \\
\hline $88-92$ & Linear Slot Diffuser (4slots) & $\begin{array}{l}0.9(2.1), 1.4(3.3), 1.9(4.5) \\
2.2(5.8), 2.7(8.6)\end{array}$ & $8 \pm 1$ \\
\hline $93-98$ & Round Ceiling Diffuser & $\begin{array}{l}0.8(2.3), 1.0(3.3), 1.1(4.4) \\
1.4(5.5), 1.9(8.3), 2.0(8.6)\end{array}$ & $8 \pm 1$ \\
\hline $99-103$ & $\begin{array}{l}\text { Louvered Face Diffuser } \\
\text { with no lip }\end{array}$ & $\begin{array}{l}1.7(2.2), 1.9(3.3), 2.1(4.4) \\
2.5(5.8), 3.3(8.6)\end{array}$ & $8 \pm 1$ \\
\hline $104-108$ & $\begin{array}{l}\text { Perforated diffuser } \\
\text { directional pattern (4way) }\end{array}$ & $\begin{array}{l}0.8(2.1), 1.4(3.3), 1.8(4.5), \\
2.2(5.8), 2.7(8.6)\end{array}$ & \\
\hline \multicolumn{4}{|c|}{ Perfect Mix } \\
\hline $109-118$ & $\begin{array}{l}\text { Round ceiling diffuser, } \\
\text { Louvered face-no lip }\end{array}$ & $\begin{array}{l}(1.1),(2.3),(3.3),(3.3),(4.5), \\
(5.7),(5.8),(7.2),(7.2),(8.6)\end{array}$ & $-5 \pm 2$ \\
\hline
\end{tabular}

Cases with underline: repeated experiments

Table 3.2: The experimental matrix (Cooling conditions/Perfect mix)

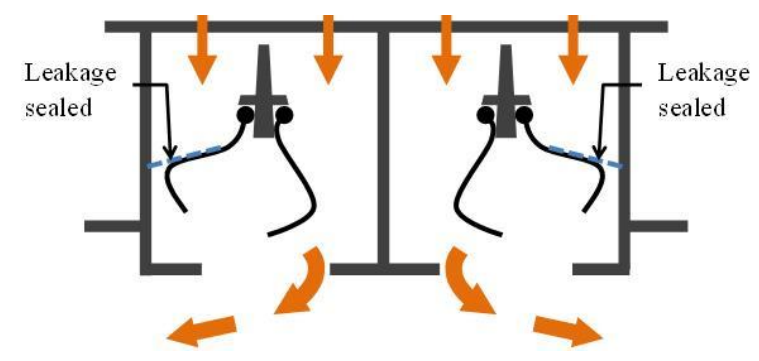

a) Horizontal flow

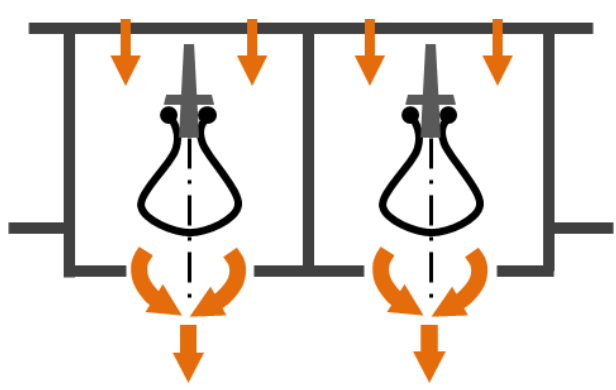

b) Vertical flow

Figure 3.3: Linear slot diffuser adjustment

\subsection{Perfect Mix Test}

The perfect mix tests were conducted as control tests to provide reference results. Perfect mix was achieved by adding three additional mixing fans in the room that secured air mixing throughout the space. The mixing fans were operated through the experiments. 
A total of eight cases with different air flow rates were conducted. Table 3.3 shows the air change effectiveness, E, standard deviation (STDV) of local air change effectiveness, $E_{i}$, and the temperature effectiveness, $\varepsilon_{T}$, in each experiment. $V$ in the table indicates the air flow rate of exhaust calculated from the measured age of air of the exhaust for each experiment. The supply air volumes displayed by the HVAC control system and calculated air flow rates were slightly different. The experimental settings were adjusted by controlling the air flow rate on the control system. However, corrections were made by the correlation of air flow rate on the control system and actual calculated air flow rate from the experiments. The air change effectiveness, $E$, was near 1.00 with almost no standard deviation in all cases. The temperature effectiveness, $\varepsilon_{T}$, was also close to 1.0 for all experiments. The results showed that the experiments were well controlled and accurate measurement would be possible to gather with this procedure.

\begin{tabular}{c|c|c|c|c}
\hline Case & $V\left[\mathrm{~m}^{3} / \mathrm{h}\right]$ & $E[-]$ & STDV of $E_{i}[-]$ & $\varepsilon_{T}[-]$ \\
\hline 109 & 71 & 0.98 & 0.01 & 1.02 \\
\hline 110 & 151 & 0.98 & 0.02 & 1.02 \\
\hline 111 & 218 & 1.00 & 0.02 & 1.02 \\
\hline 112 & 222 & 0.96 & 0.02 & 1.01 \\
\hline 113 & 299 & 0.98 & 0.02 & 1.02 \\
\hline 114 & 382 & 1.01 & 0.02 & 1.00 \\
\hline 115 & 391 & 0.98 & 0.03 & 1.01 \\
\hline 116 & 479 & 0.97 & 0.03 & 1.01 \\
\hline 117 & 479 & 1.00 & 0.04 & 1.02 \\
\hline 118 & 578 & 0.97 & 0.04 & 1.00 \\
\hline
\end{tabular}

Table 3.3: Perfect mixing test results (control tests introduced to examine experimental setup) 


\subsection{Uncertainty of the Measurement}

The uncertainty of measurements of ventilation effectiveness depends on several factors, such as accuracy of the instruments, air flow adjustment, and pressure balancing. In general, ASHRAE Standard 129 (2002) discusses various factors that cause significant measurement errors. The total uncertainty in the measured values of air change effectiveness was assumed to be approximately $\pm 16 \%$, and the standard mentioned that this value can be considered the maximum uncertainty of the measured value. Cui et al. (2015) demonstrated the uncertainty of $\mathrm{CO}_{2}$ tracer gas decay method for measuring air change rate related to sensors and calculation method. Uncertainty related to various insitu $\mathrm{CO}_{2}$ sensors was $5 \%$ for the majority of sensors, $5 \%$ for the multi-points calculation and $12 \%$ for the two-points calculation.

Accuracy may be assessed through comparison of repeated experiments. A total of seven sets of experiments were repeated twice to evaluate uncertainty of the experiments. Repeated experiments were randomly selected including two sets of the perfect mix test. Table 3.4 shows the uncertainty of the air change efficiency from repeated experiments. Each index of air change efficiency $\left(E_{i}, E_{\text {low }}, E_{\text {high }}\right.$ and $\left.E\right)$ were compared. Differences between repeated experiments were computed as a percentage. All difference value in percentage per $E_{i}, E_{\text {low }}, E_{\text {high }}$ and $E$ were rearranged in ascending order, respectively. The minimum, $5^{\text {th }}, 25^{\text {th }}, 50^{\text {th }}, 75^{\text {th }}$ and $95^{\text {th }}$ percentile, maximum, and average values are shown in the table. The uncertainty of $E_{i}$ was $6 \%$ on average and $14 \%$ in $95^{\text {th }}$ percentile. Overall, uncertainty of $E_{\text {low }}, E_{\text {high }}$ and $E$ was about $6 \%$ on average and $12 \%$ in maximum. 


\begin{tabular}{lcccccccc}
\hline & Min. & $\begin{array}{c}5^{\text {th }} \\
\text { Percentile }\end{array}$ & $\begin{array}{c}25^{\text {th }} \\
\text { Percentile }\end{array}$ & Medium & $\begin{array}{c}75^{\text {th }} \\
\text { Percentile }\end{array}$ & $\begin{array}{c}95^{\text {th }} \\
\text { Percentile }\end{array}$ & Max. & Ave. \\
\hline $\begin{array}{l}E_{i} \\
(\mathrm{~N}=122)\end{array}$ & 0 & $1 \%$ & $3 \%$ & $5 \%$ & $9 \%$ & $14 \%$ & $19 \%$ & $6 \%$ \\
$\begin{array}{l}E_{\text {low }} \\
(\mathrm{N}=7)\end{array}$ & 0 & - & - & $7 \%$ & - & - & $12 \%$ & $6 \%$ \\
$\begin{array}{l}E_{\text {high }} \\
(\mathrm{N}=7)\end{array}$ & 1 & - & - & $4 \%$ & - & - & $11 \%$ & $5 \%$ \\
$E$ & & & - & $4 \%$ & - & - & $11 \%$ & $6 \%$ \\
$(\mathrm{~N}=7)$ & 0 & - & - & $4 \%$ & & & & \\
\hline
\end{tabular}

$\mathrm{N}$ : number of the data compared.

Table 3.4: Uncertainty of air change effectiveness defined by experiments repetition 


\section{Chapter 4: Results and Discussion}

This chapter presents the results and discussions of the experiments in terms of diffuser performance and variance of local air change effectiveness. Section 4.1 summarizes the diffuser performance analysis. Section 4.2 then describes the results of variance evaluation. In addition, the correlation between the air change effectiveness and the temperature effectiveness was introduced. Section 4.3 and 4.4 presents the discussions of the results.

\subsection{Diffuser Performance Analysis}

This section examines the results for experimental settings in terms of the indices explained in Chapter 2. The results were summarized for diffusers under heating conditions and cooling conditions in the following subsection. In addition, the influence of different internal loads on each diffuser is also analyzed under heating conditions.

\subsubsection{Heating mode}

\section{Air change Effectiveness and Temperature Effectiveness}

Figure 4.1 shows the results of the air change effectiveness, $E$, under heating conditions with $\Delta T=-5 \pm 2$. Triangle plots show the ADPI value from the Liu (2016) study with the right side of $\mathrm{y}$-axis as reference. The recommended range of $T_{0.25} / L$ is also indicated in the graph. The solid marks indicate that supply air temperatures, $T_{S A}$, were less than $8{ }^{\circ} \mathrm{C}$ above average occupied space temperature $\langle T\rangle_{0}$. Marks without fill indicate that supply air temperatures were $8{ }^{\circ} \mathrm{C}$ or more above $\langle T\rangle_{0}$ for $E$. Overall, the value of $E$ within the recommended range of $T_{0.25} / L$ was from 0.56 to 0.87 . A similar 
tendency was found among all diffusers that $E$ was significantly decreased when $T_{0.25} / L$ was smaller than the recommended range. At the same time, thermal stratification was also high in most cases as $T_{S A}$ was $8{ }^{\circ} \mathrm{C}$ or higher than $<T>_{0}$. The smallest $E$ was approximately 0.42 among all tested diffusers. Linear slot diffusers and perforated diffusers directional pattern (4way) had the lower $E$ at the minimum recommended range of $T_{0.25} / L$. Linear slot diffusers had the highest $E$ at the maximum recommended range of $T_{0.25} / L$. $E$ sharply increased as $T_{0.25} / L$ increased. To maintain $E$ around 0.8 as noted in ASHRAE standard 55, $T_{0.25} / L$ should remain higher than 2.7 for linear slot diffusers, 1.7 for round ceiling diffusers, and 3.2 for louvered face diffuser without lip. Perforated diffusers directional pattern (4way) did not reach 0.8 , and the maximum air change effectiveness found was 0.72 .

Figure 4.2 shows the results of the temperature effectiveness under heating conditions with $\Delta T=-5 \pm 2$. Overall, the value of temperature effectiveness, $\varepsilon_{T}$, within the recommended range of $T_{0.25} / L$ was from 0.56 to 0.75 . The range of $\varepsilon_{T}$ was very similar between the linear slot, round ceiling, and louvered face without lip diffusers. The perforated lip diffuser was slightly less than other three diffusers. Similar to the $E, \varepsilon_{T}$ increased as $T_{0.25} / L$ increased within the recommended rage. However, $\varepsilon_{T}$ slightly increased as $T_{0.25} / L$ decreased below the recommended value. It was considered that when $T_{0.25} / L$ became smaller than the recommended range, the dominant factor that characterizes a mixture of the space gradually changed from the supply jet from the diffuser to the down draft caused by cold wall surface. This down draft caused high thermal stratification in the space. On the other hand, $\Delta T$ also slightly increased within the range of $\pm 2{ }^{\circ} \mathrm{C}$ as $T_{0.25} / L$ decreased. Since $\varepsilon_{T}$ examines the ratio of $\left(T_{S A}-T_{E A}\right)$ and $\left(T_{S A}\right.$ $\left.-<T>_{0}\right)$ the different ratio of the gradual increase of $\left(T_{S A}-T_{E A}\right)$ and $\left(T_{S A}-<T>_{0}\right)$ caused a slight increase of $\varepsilon_{T}$. 


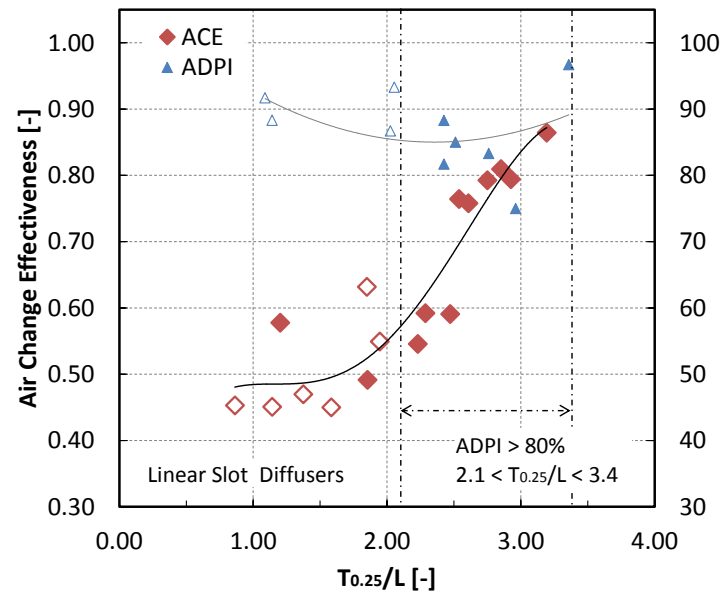

a) Linear Slot Diffusers (Case 1-9, 16-24)

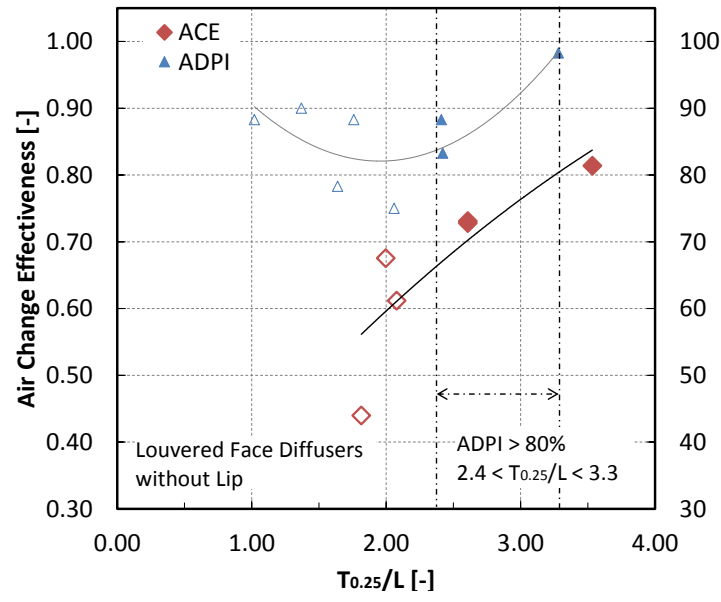

c) Louvered Face Diffusers without Lip (Case 51-56)

* mark with fill: $T_{S A}$ less than $8{ }^{\circ} \mathrm{C}$ above $<T>_{0}$

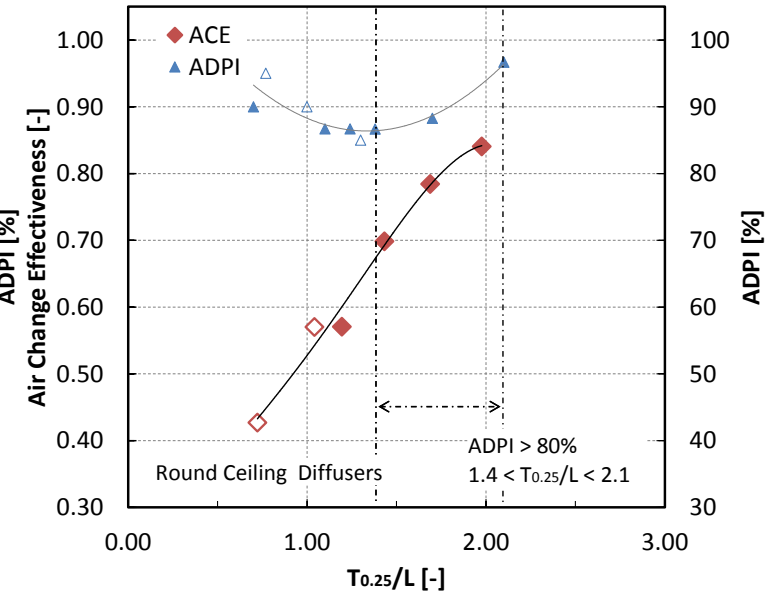

b) Round Ceiling Diffusers (Case 38-43)

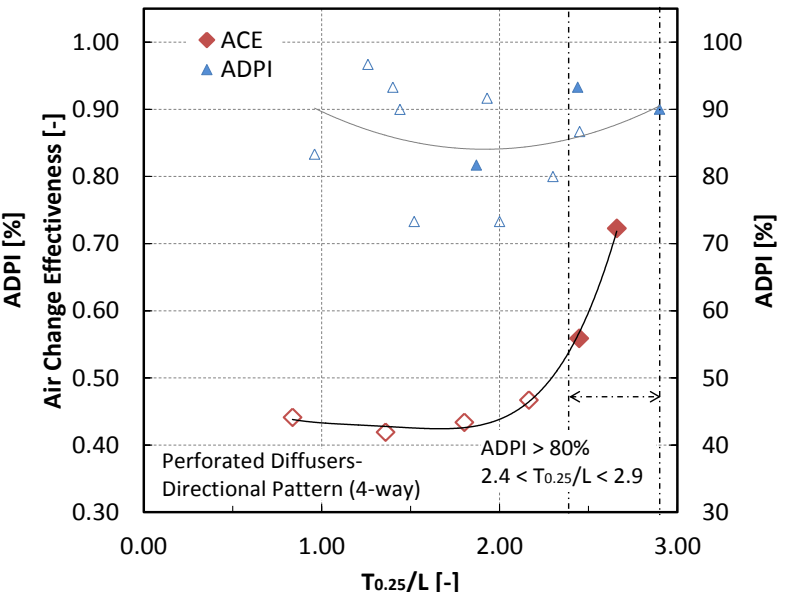

d) Perforated Diffusers Directional Pattern (4way) (Case 57-62)

Figure 4.1: $\quad T_{0.25} / L$ vs. Air change effectiveness, $E$, (left side y-axis) and $A D P I$ from Liu's (2016) experiments (right side y-axis) under heating conditions with $\Delta T=-5 \pm 2$. 


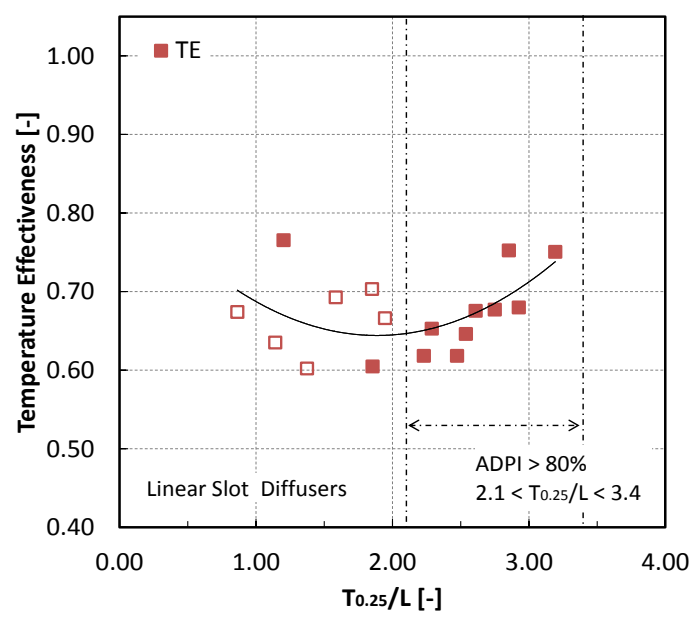

a) Linear Slot Diffusers (Case 1-9, 16-24)

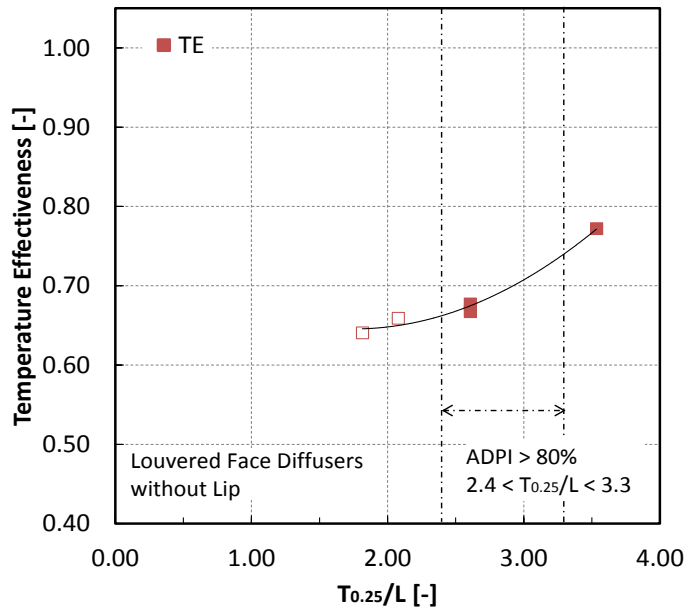

c) Louvered Face Diffusers without Lip (Case 51-56)

* mark with fill: $T_{S A}$ less than $8^{\circ} \mathrm{C}$ above $\langle T\rangle_{0}$

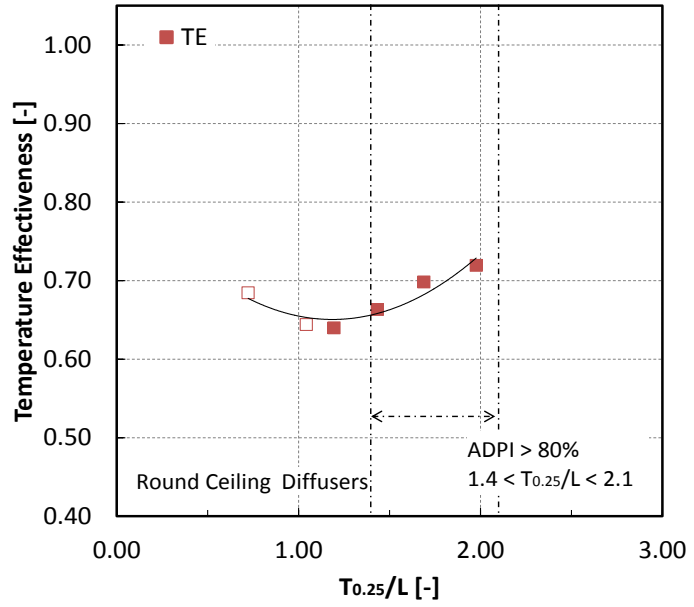

b) Round Ceiling Diffusers (Case 38-43)

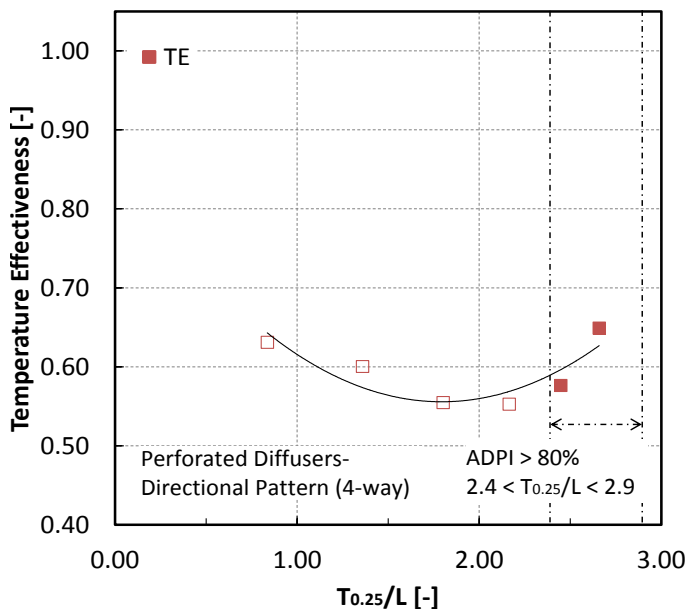

d) Perforated Diffusers Directional Pattern (4way) (Case 57-62)

Figure 4.2: $\quad T_{0.25} / L$ vs. temperature effectiveness, $\varepsilon_{T}$, under heating conditions with $\Delta T=-$ $5 \pm 2$.

\section{Effects of Internal Load to Air Change Effectiveness and Temperature Effectiveness}

Figure 4.3 shows air change effectiveness, $E$, and temperature effectiveness, $\varepsilon_{T}$, of linear slot diffusers under the heating condition with an internal load of $\Delta T=-2 \pm 2$ and $\Delta T=-5 \pm 2$. Both $E$ and $\varepsilon_{T}$ were higher under $\Delta T=-2 \pm 2$ conditions than under $\Delta T=-5 \pm 2$ at 
the same $T_{0.25} / L$. The largest value of the $E$ was 0.87 at the $\Delta T=-5 \pm 2$ condition, and 1.00 at the $\Delta T=-2 \pm 2$ condition. Under $\Delta T=-2 \pm 2$ conditions, $E$ was in range from 0.65 to 1.00 and $\varepsilon_{T}$ was from 0.77 to 0.95 within the recommended range of $T_{0.25} / L$. No significant difference between $\Delta T=-2 \pm 2$ and $\Delta T=-5 \pm 2$ was seen when $T_{0.25} / L$ was less than 1.5 . The same reason as the previous explanation was assumed: when $T_{0.25} / L$ was less than 1.5 , down draft from the cold wall surface became the dominant force, and it did not make significant changes to $E$ of the space. When $T_{0.25} / L$ was greater than $2.5, E$ was close to 1.00. However, $\varepsilon_{T}$ was approximately 0.80 when $T_{0.25} / L$ was 2.5 and it increased as $T_{0.25} / L$ exceeded 2.5. Significant increase of $\varepsilon_{T}$ was also found with the $\Delta T=-2 \pm 2$ condition when $T_{0.25} / L$ was between 1.5 to 2.5 , and the slope of the increase was higher in the $\Delta T=-2 \pm 2$ condition than in the $\Delta T=-5 \pm 2$ condition.

Figure 4.4 shows air change effectiveness, $E$, and temperature effectiveness, $\varepsilon_{T}$, of round ceiling diffusers under the heating condition with internal load of $\Delta T=-2 \pm 2, \Delta T=$ $5 \pm 2$ and $\Delta T=-8 \pm 2$. Both $E$ and $\varepsilon_{T}$ were higher under $\Delta T=-2 \pm 2$ conditions than under $\Delta T=-$ $5 \pm 2$ conditions and higher under $\Delta T=-5 \pm 2$ conditions than under $\Delta T=-8 \pm 2$ conditions at the same $T_{0.25} / L$ within the recommended range. The largest values of $E$ were $0.95,0.85$ and 0.73 with $\Delta T=-2 \pm 2, \Delta T=-5 \pm 2$, and $\Delta T=-8 \pm 2$, respectively. Under $\Delta T=-2 \pm 2$ conditions, $E$ was near 1.0 within the recommended range of $T_{0.25} / L$. $E$ was sharply decreased when $T_{0.25} / L$ went smaller than the recommended range. $\varepsilon_{T}$ was slightly increased (from 0.80 to 0.86 within recommended range) while $E$ was stayed around 1.00. The lowest $E$ was about 0.35 at a $T_{0.25} / L$ value of 0.6 under the $\Delta T=-8 \pm 2$ condition. The difference between various $\Delta T$ values was minimal for $T_{0.25} / L$ as 0.6 , and this point can be interpreted as the transition point. $\varepsilon_{T}$ of the $\Delta T=-5 \pm 2$ and $\Delta T=-8 \pm 2$ conditions were almost same as when $T_{0.25} / L$ was smaller than the recommended range. 


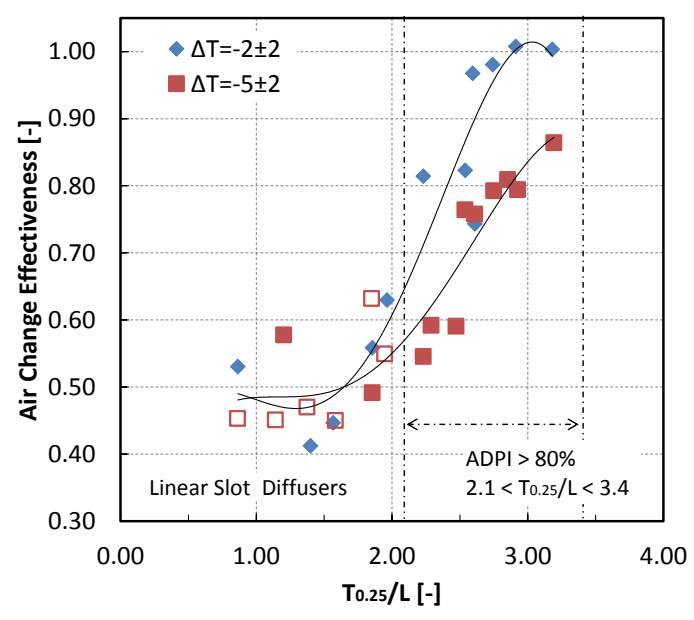

a) Air Change Effectiveness

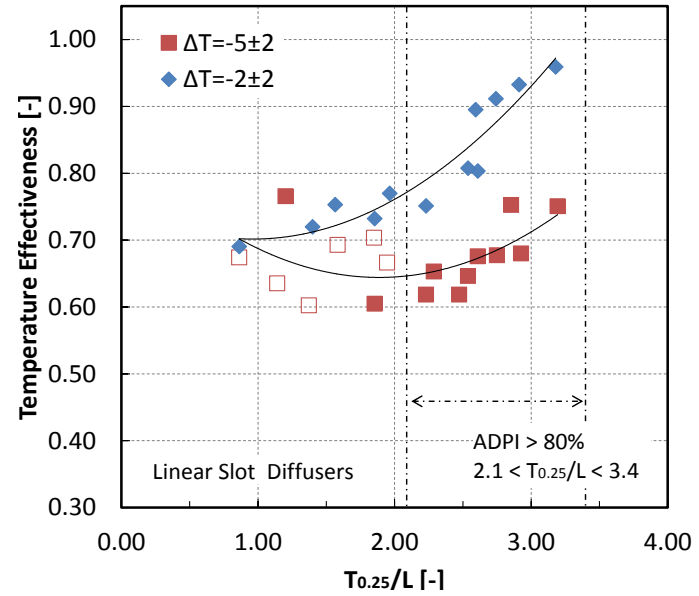

b) Temperature Effectiveness

* mark with fill: $T_{S A}$ less than $8{ }^{\circ} \mathrm{C}$ above $\left\langle T>_{0}\right.$, ${ }^{* *}$ mark without fill: $T_{S A} 8^{\circ} \mathrm{C}$ or more above $\langle T\rangle_{0}$

Figure 4.3: $\quad T_{0.25} / L$ vs. air change effectiveness, $E$, and temperature effectiveness, $\varepsilon_{T}$, of Linear Slot Diffusers under heating conditions with different $\Delta T$ (Cases 1-9, 16-24 and Cases 10-15, 25-30)

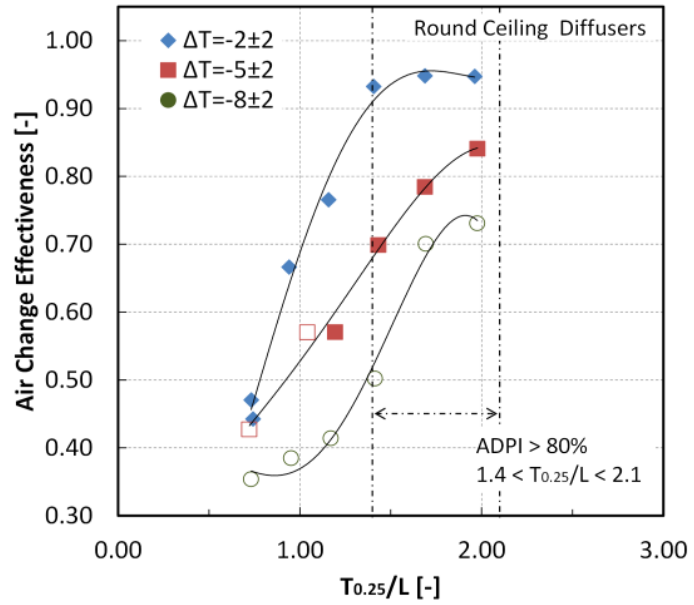

a) Air Change Effectiveness

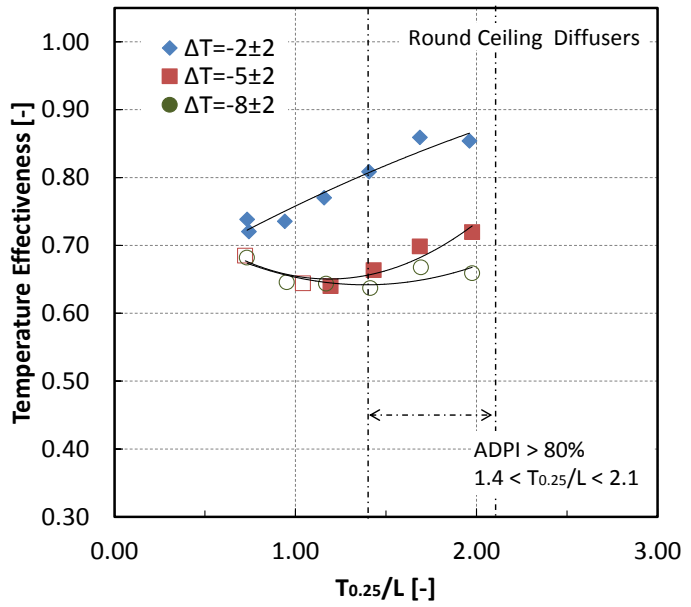

b) Temperature Effectiveness

* mark with fill: $T_{S A}$ less than $8{ }^{\circ} \mathrm{C}$ above $\left\langle T>_{0},{ }^{* *}\right.$ mark without fill: $T_{S A} 8^{\circ} \mathrm{C}$ or more above $\langle T\rangle_{0}$

Figure 4,4: $\quad T_{0.25} / L$ vs air change effectiveness, $E$, and temperature effectiveness, $\varepsilon_{T}$, of Round Ceiling Diffusers under heating conditions with different $\Delta T$ (Cases 31-37, Cases 38-43 and Cases 44-50) 


\subsubsection{Cooling Mode}

\section{Air Change Effectiveness and Temperature Effectiveness}

Figure 4.5 shows the results of the air change effectiveness, $E$, under cooling conditions with $\Delta T=8 \pm 1$. Similar to Figure 4.1, this figure's triangle plots show ADPI values from Liu's (2016) study as a reference using the right side y-axis. The recommended $T_{0.25} / L$ is also indicated on the graph. Overall, $E$ was in the range of 0.98 to 1.16 within the recommended range of $T_{0.25} / L$ regarding ADPI. $E$ was greater than or equal to 1.00 in all cooling conditions. $E$ was slightly greater when $T_{0.25} / L$ decreased. It is possible that the jet from the diffuser detached from the ceiling and dived into the occupant zone when $T_{0.25} / L$ was small. As local air change effectiveness, $E_{i}$, was measured in an occupant zone, this effect ended with slightly higher $E$. However, short throw length tended to decrease ADPI, and it may increase draft risk as indicated by plots of ADPI.

Figure 4.6 displays the results of the temperature effectiveness, $\varepsilon_{T}$, under cooling conditions with an internal load of $\Delta T=8 \pm 1$. Overall, $\varepsilon_{T}$ was in the range of 0.92 to 1.11 within the recommended range of $T_{0.25} / L$. Similar to the $E, \varepsilon_{T}$ was slightly higher when $T_{0.25} / L$ was small, and it decreased as $T_{0.25} / L$ increased. The round ceiling diffusers showed the smallest slope among the four diffusers tested, and $\varepsilon_{T}$ was close to 1.00 in every measured $T_{0.25} / L$. 

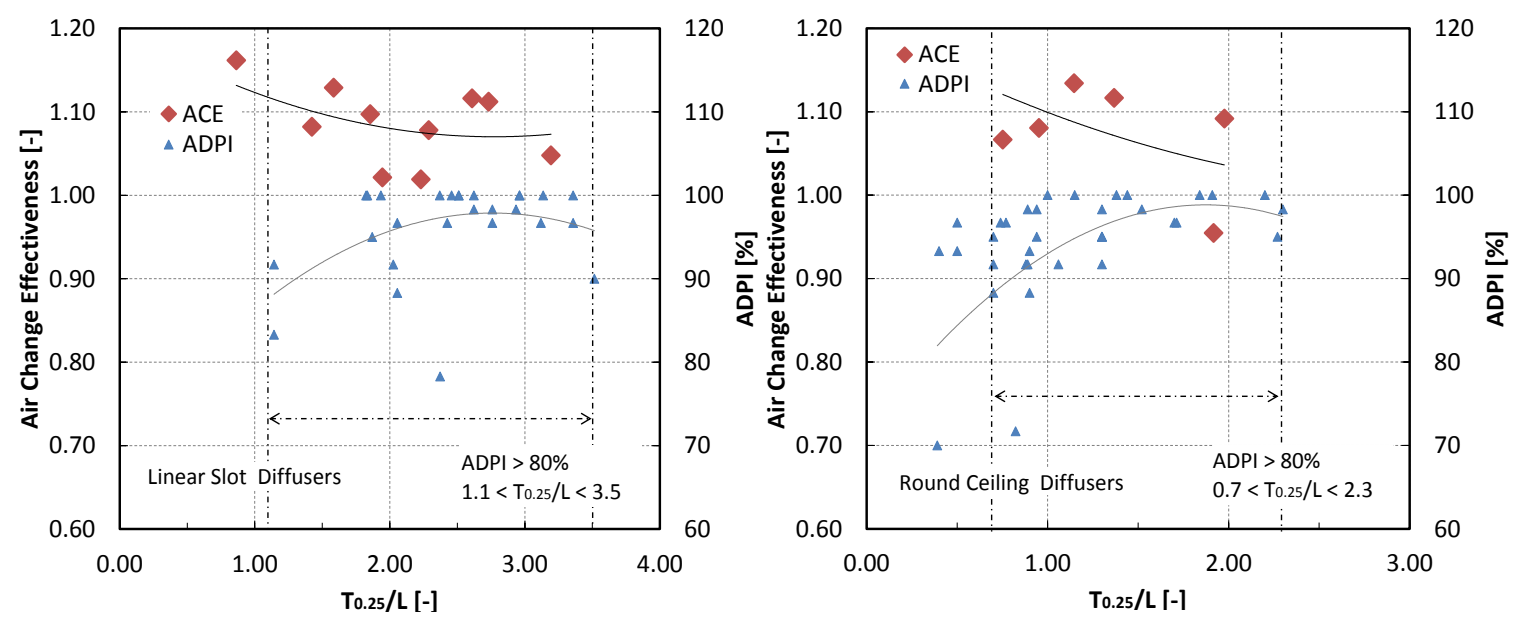

a) Linear Slot Diffusers (Case 83-87, 88-92)

b) Round Ceiling Diffusers (Case 93-98)
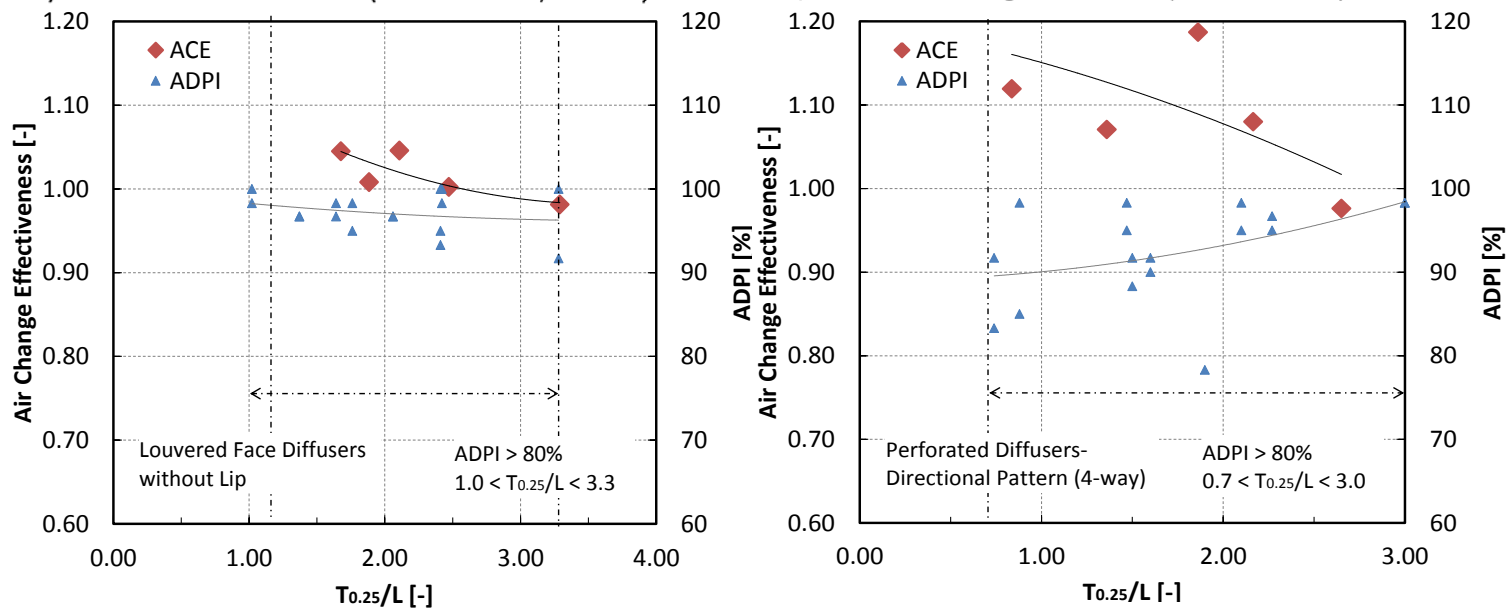

c) Louvered Face Diffusers without Lip (Case 99-103)

d) Perforated Diffusers Directional Pattern (4way) (Case 104-108)

Figure 4.5: $\quad T_{0.25} / L$ vs. air change effectiveness, $E$, (left side y-axis) and ADPI from Liu's (2016) experiments (right side y-axis) under cooling conditions with an internal load of $\Delta T=8 \pm 1$. 

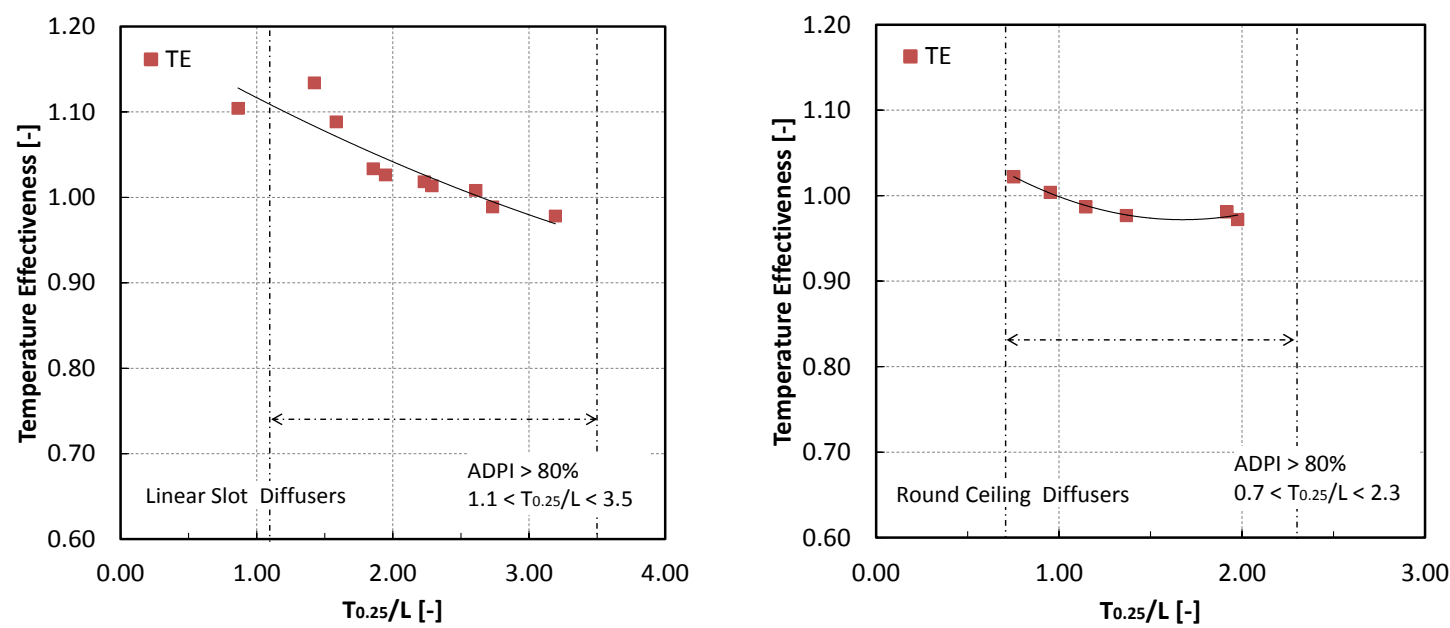

a) Linear Slot Diffusers (Case 83-87, 88-92)

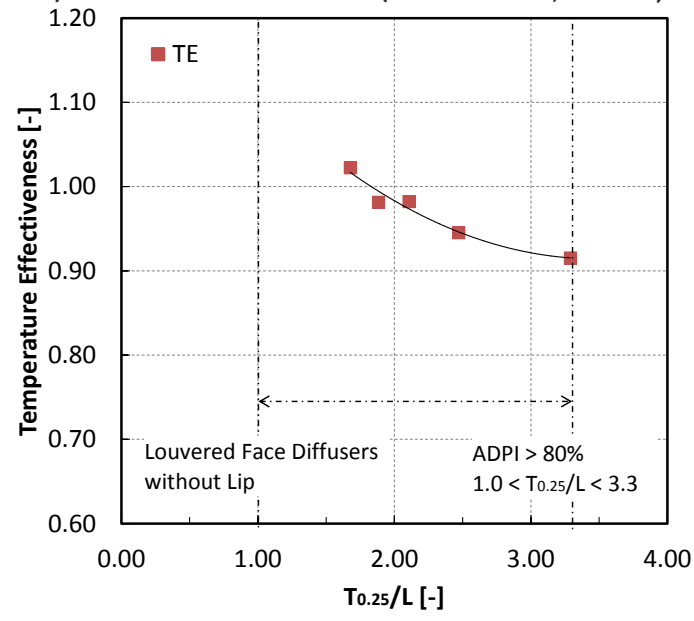

c) Louvered Face Diffusers without Lip (Case 99-103)

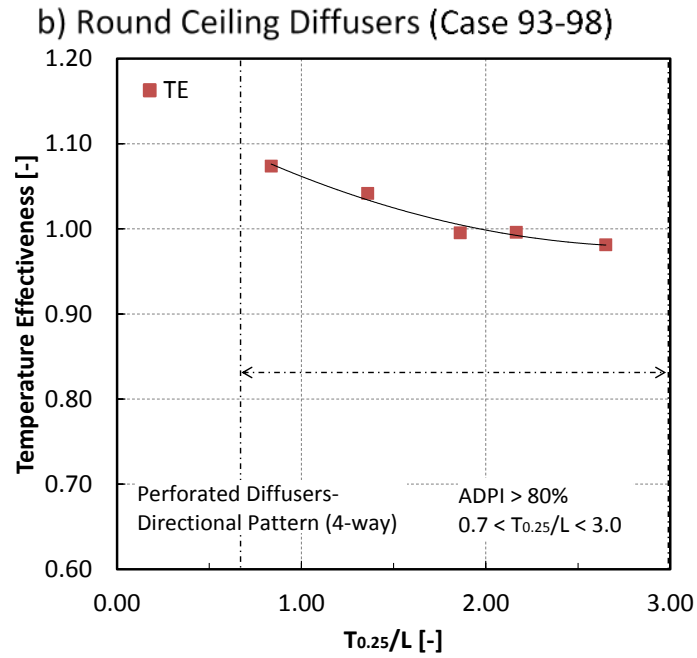

d) Perforated Diffusers Directional Pattern (4way) (Case 104-108)

Figure 4.6: $\quad T_{0.25} / L$ vs. temperature effectiveness, $\varepsilon_{T}$, under cooling conditions with an internal load of $\Delta T=8 \pm 1$.

\subsection{Variance Analysis}

This section examines the vertical, horizontal and overall variance of air change effectiveness in the test space per experimental settings. In addition, the range of temperature effectiveness and the correlation of air change effectiveness between temperature effectiveness are also analyzed. 


\subsubsection{Vertical Variance in the Test Space}

To evaluate the vertical variances of air change effectiveness, differences between high measuring plane and low measuring plane were examined. The vertical variances of air change effectiveness as a percentage at the point of $i, B_{i}$, is defined as

$$
B_{i}=A B S\left(1-\frac{E_{i, h i g h}}{E_{i, \text { low }}}\right) \times 100 \quad[\%]
$$

in which $i$,high and $i$, low are the local air change effectiveness of the high measuring plane $(1.5 \mathrm{~m})$ and low measuring plane $(0.9)$ at the same horizontal measuring point, respectively. Figure 4.7 displays the vertical variances of local ventilation effectiveness as a percentile. All $B_{i}$ per experimental settings were rearranged in ascending order. The $5^{\text {th }}, 25^{\text {th }}, 50^{\text {th }}, 75^{\text {th }}$ and $95^{\text {th }}$ percentile values are shown in the figure. The $75^{\text {th }}$ percentile values for all cases were less than $16 \%$. The median values of all conditions were less than or equal to 7\%. Vertical variance for Cases 10-15 and Cases 25-30 (linear slot diffuser and $\Delta T=-2 \pm 2$ ) were slightly higher than the other conditions in median, $75^{\text {th }}$ and $95^{\text {th }}$ percentile. Variances of Cases 1-82 (overall heating conditions) and Cases 83-108 (overall cooling conditions) were almost same, and the variance was less than $11 \%$ in $75^{\text {th }}$ percentile. Additionally, the variance of Cases 1-62 (overall heating conditions with horizontal flow) and Cases $83-108$ were equal to $21 \%$ in $95^{\text {th }}$ percentile and $10 \%$ in $75^{\text {th }}$ percentile. It is considered that operation mode (heating or cooling mode) may not have major impact to vertical variance. Cases 63-82 (vertical flow with linear slot diffusers under heating conditions) had lower variances than Cases 1-62 (horizontal flow diffusers under heating conditions) in $75^{\text {th }}$ and $95^{\text {th }}$ percentile. It is implied that vertical momentum 
from the diffuser improved the mixture. Cases 1-118 (all experiments) were equal to $19 \%$ in $95^{\text {th }}$ percentile, $8 \%$ in $75^{\text {th }}$ percentile and $4 \%$ in median. The most of the variances found were close to or less than the uncertainty of the measurement discussed in the Chapter 3.

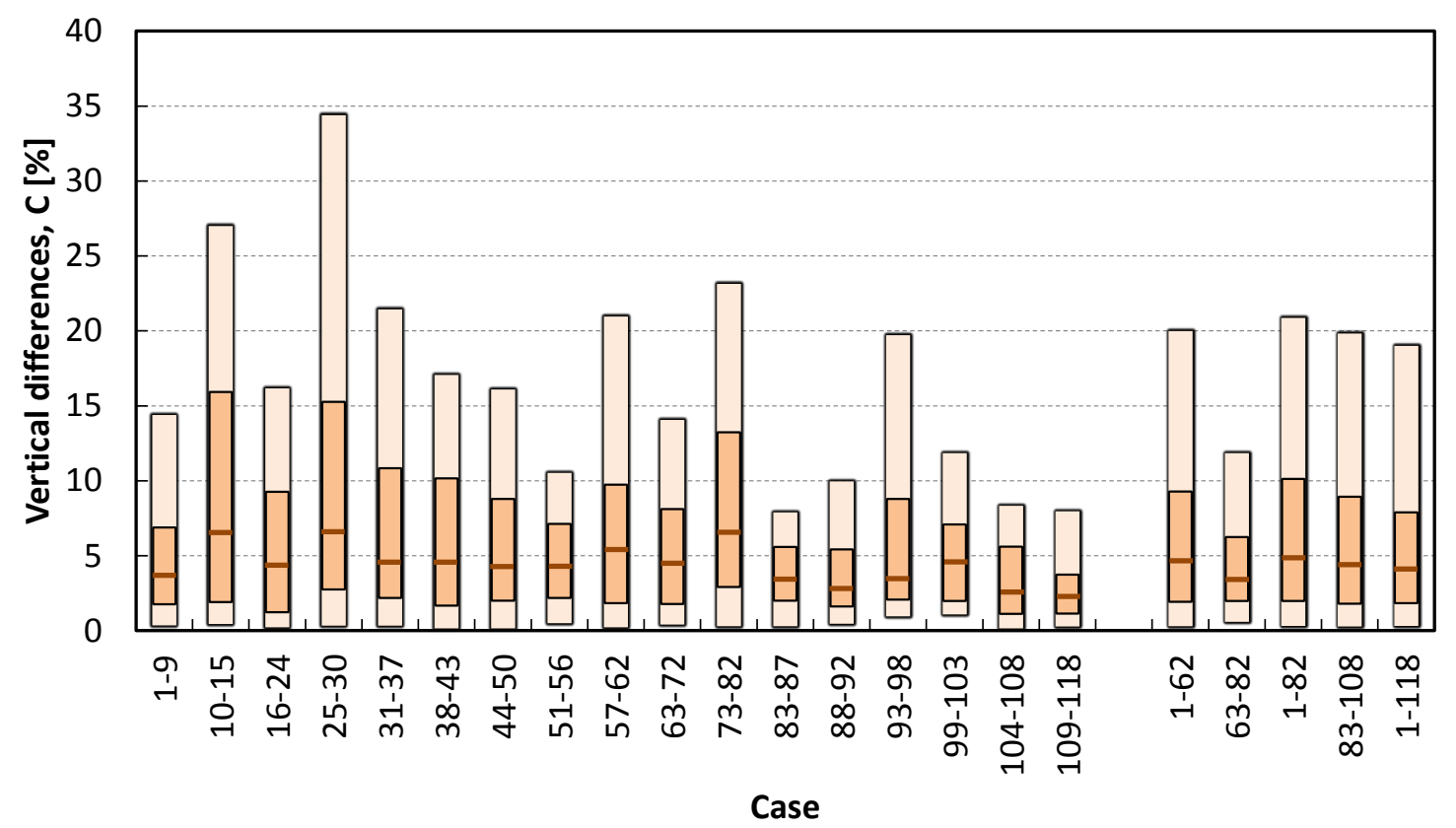

Figure 4.7: Vertical variances of local air change effectiveness as a percentile.

\subsubsection{Horizontal and Overall Variance in the Test Space}

To evaluate the horizontal and overall variance of air change effectiveness in different experimental conditions, standard deviation was converted to a percentage by using Equation 4.2. The standard deviation of air change effectiveness as a percentage per low measuring plane, high measuring plane or overall test space, $C_{j}$, is defined as 


$$
C_{j}=A B S\left(1-\frac{\sigma_{j}}{E_{j}}\right) \times 100 \quad[\%]
$$

in which $\sigma_{j}$ is the standard deviation of air change effectiveness per high measuring plane, low measuring plane and overall test space, and $E_{j}$ is whether $E_{\text {low }}, E_{\text {high }}$ or $E$. Table 4.1 displays the horizontal and overall standard deviations of air change effectiveness in percentage. Cases 10-15 and Cases 25-30 had slightly higher $C_{j, \text { Max }}$ in both horizontal plane and overall space. It was considered that a low buoyancy effect with little momentum caused moderate mixing in the test space, and this resulted in higher variances in the overall test space. Cases 109-118 (perfect mix) had the lowest variances. The results showed the air was well mixed by mixing fans as designed. There was no significant difference between variances in high measuring plane and in low measuring plane. In addition, there was no significant difference between Cases 1-82 (overall heating conditions) and Cases 83-108 (overall cooling conditions). In Cases 1-118 (all experiments), $C_{a v e}$ was $5 \%$ and $C_{M a x}$ was $16 \%$ in the high plane, low plane and overall test space. Similar to the vertical variances, the most of the variances were close to or less than the uncertainty. 


\begin{tabular}{l|l|l|l|l|l|l|l|l|l}
\hline \multirow{2}{*}{ Cases \# } & \multicolumn{3}{|c|}{ Low Plane $(+0.9 \mathrm{~m})$} & \multicolumn{3}{c|}{ High Plane $(+1.5 \mathrm{~m})$} & \multicolumn{3}{c}{ Overall test space } \\
\cline { 2 - 10 } & $\begin{array}{l}\text { C } \\
\text { low,Ave. }\end{array}$ & $\begin{array}{l}\text { C } \\
\text { low,Min. }\end{array}$ & $\begin{array}{l}\text { C } \\
\text { low,Max. }\end{array}$ & $\begin{array}{l}\text { C } \\
\text { high,Ave. }\end{array}$ & $\begin{array}{l}\text { C } \\
\text { high,Min. }\end{array}$ & $\begin{array}{l}\text { C } \\
\text { high,Max. }\end{array}$ & C $_{\text {Ave. }}$ & C $_{\text {Min. }}$ & C $_{\text {Max. }}$ \\
\hline $1-9$ & 3 & 2 & 8 & 6 & 2 & 10 & 5 & 2 & 8 \\
\hline $10-15$ & 6 & 3 & 15 & 7 & 3 & 16 & 8 & 3 & 14 \\
\hline $16-24$ & 4 & 2 & 5 & 7 & 3 & 10 & 6 & 3 & 8 \\
\hline $25-30$ & 8 & 5 & 12 & 7 & 3 & 14 & 9 & 4 & 16 \\
\hline $31-37$ & 4 & 2 & 8 & 6 & 3 & 8 & 6 & 2 & 9 \\
\hline $38-43$ & 3 & 2 & 6 & 5 & 4 & 8 & 5 & 3 & 7 \\
\hline $44-50$ & 6 & 3 & 9 & 4 & 1 & 8 & 5 & 3 & 9 \\
\hline $51-56$ & 3 & 2 & 3 & 5 & 3 & 6 & 4 & 3 & 5 \\
\hline $57-62$ & 3 & 2 & 8 & 7 & 4 & 11 & 6 & 3 & 8 \\
\hline $63-72$ & 4 & 2 & 9 & 5 & 3 & 10 & 5 & 3 & 7 \\
\hline $73-82$ & 4 & 2 & 6 & 5 & 4 & 7 & 6 & 3 & 12 \\
\hline $83-87$ & 3 & 1 & 4 & 4 & 4 & 5 & 4 & 3 & 4 \\
\hline $88-92$ & 4 & 2 & $5 \mathrm{~S}$ & 5 & 4 & 8 & 4 & 4 & 6 \\
\hline $93-98$ & 6 & 3 & 9 & 4 & 3 & 6 & 5 & 3 & 9 \\
\hline $99-103$ & 3 & 2 & 4 & 4 & 4 & 6 & 4 & 3 & 5 \\
\hline $104-108$ & 5 & 3 & 7 & 5 & 4 & 8 & 5 & 4 & 7 \\
\hline $109-118$ & 2 & 2 & 3 & 3 & 1 & 5 & 3 & 1 & 4 \\
\hline & & & & & & & & & \\
\hline
\end{tabular}

\begin{tabular}{l|l|l|l|l|l|l|l|l|l}
\hline $1-62$ & 4 & 2 & 15 & 6 & 1 & 16 & 6 & 2 & 16 \\
\hline $63-82$ & 4 & 2 & 9 & 5 & 3 & 10 & 6 & 3 & 12 \\
\hline $1-82$ & 4 & 2 & 15 & 6 & 1 & 16 & 6 & 2 & 16 \\
\hline $83-108$ & 4 & 1 & 9 & 5 & 3 & 8 & 4 & 3 & 9 \\
\hline $1-118$ & 4 & 1 & 15 & 5 & 1 & 16 & 5 & 1 & 16 \\
\hline
\end{tabular}

Table 4.1: Horizontal and overall standard deviations of air change effectiveness as a percentage 


\subsubsection{Correlation of Air Change Effectiveness with Temperature Effectiveness}

Figure 4.8 displays the minimum, average and maximum of the temperature effectiveness, $\varepsilon_{T}$. The average $\varepsilon_{T}$ values were greater with lower heating loads under heating conditions (comparing Cases 1-9 and 10-15, Cases 16-24 and 25-30, Cases31-37, 38-43 and 44-50). The average $\varepsilon_{T}$ value among the heating cases varied from 0.6 to 0.9 . However, in cooling cases average $\varepsilon_{T}$ values were nearly 1.0 . The differences between maximum and minimum of $\varepsilon_{T}$ were smaller in the cooling cases.

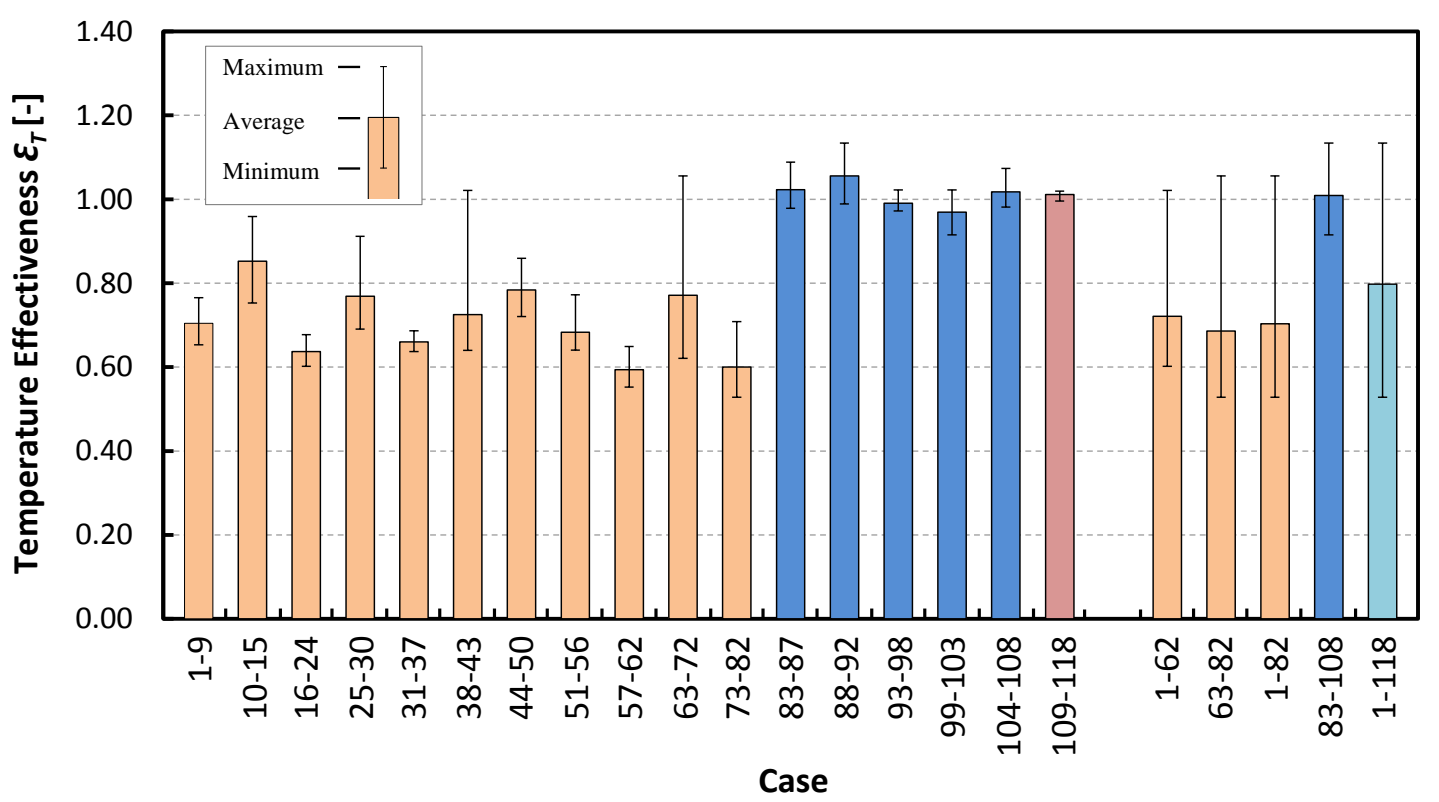

Figure 4.8: Temperature effectiveness $\varepsilon_{T}$ for experimental settings.

Figure 4.9 displays the correlation of temperature effectiveness, $\varepsilon_{T}$, and air change

effectiveness, $E$. Second order polynomial curve fitting was applied to generate the profile of $\varepsilon_{T}$ and $E$. The $E$ was near 1.0 when $\varepsilon_{T}$ was also nearly 1.0, and $E$ decreased as $\varepsilon_{T}$ decreased. 


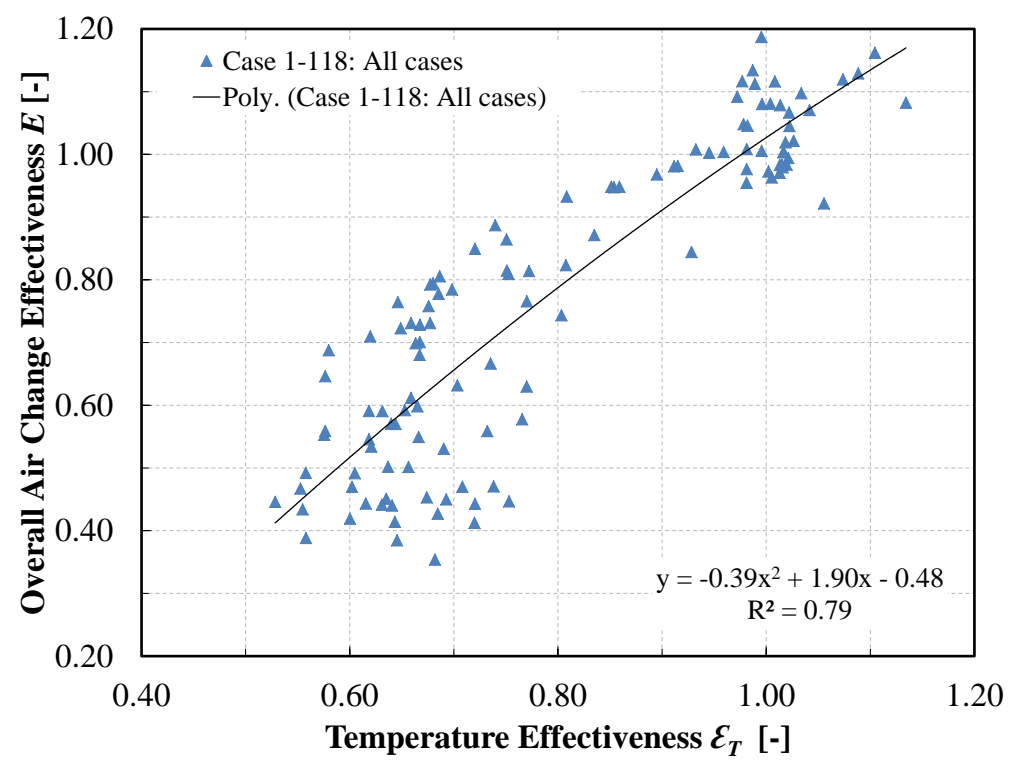

Figure 4.9: Correlation between temperature effectiveness, $\varepsilon_{T}$, and overall air change effectiveness, $E$.

\subsection{Discussion on the Diffuser Performance Analysis}

Table 4.2 provides the summary of the range of the air change effectiveness, $E$, and the temperature effectiveness, $\varepsilon_{T}$, within the range of recommended $T_{0.25} / L$ in terms of ADPI from Liu's (2016) research. This table was created with the intention to help HVAC designers select diffusers and air flow rate for all air heating and cooling systems. The data shown for heating in the table are from the cases in which the internal load was $\Delta T=-5 \pm 2$. The range of loads for $E$ and $\varepsilon_{T}$ within the recommended range of $T_{0.25} / L$ were calculated from $\Delta T\left(T_{S A}\right.$ and $\left.T_{E A}\right)$ and the air flow rate of the exhaust air stream. The experiments in this study had a wider range than the experiments for the ADPI study because this study targeted control of $\Delta T$ to examine effects of thermal stratification on the air change effectiveness. 
All the diffusers showed the following similar results: both $E$ and $\varepsilon_{T}$ increased as $T_{0.25} / L$ increased under heating conditions and slightly decreased as $T_{0.25} / L$ increased under cooling conditions. It could be possible that $E$ decreased to less than 0.80 , as referred in the ASHRAE Standard 62.1 (2010) even when the supply air temperature $T_{S A}$ is less than an $8{ }^{\circ} \mathrm{C}$ below than average temperature in occupied space $\left\langle T>_{0}\right.$. A wider range of $T_{0.25} / \mathrm{L}$ is allowed under cooling conditions than heating conditions, meaning that a smaller $T_{0.25} / L$ value is accepted under cooling conditions than would be accepted under heating conditions. However, the air change effectiveness may significantly decrease when $T_{0.25} / L$ is small under heating conditions. The perforated diffuser directional pattern (4way) showed slightly lower $E$ and $\varepsilon_{T}$ under heating conditions. The linear slot diffusers have greater range in air change effectiveness under heating conditions. Regardless of the diffuser type, $E$ and $\varepsilon_{T}$ were approached or exceeded 1.00 within recommended range.

Mixing ventilation systems are utilized in various HVAC systems such as a VAV system with constant supply temperature or CAV system with variable supply air temperature. For most of the all-air-heating and cooling system, the same system is used for both heating and cooling. In general, the cooling load is the dominant factor for sizing the coils, fans, ducts and diffusers, so diffusers are usually selected by the considering cool mode. However, the range capable of achieving good mixing under the heating condition is not as great. $E$ decreases when $T_{0.25} / L$ is small under the heating mode while still maintaining a high ADPI and air change effectiveness under cooling mode. This research provides fundamental data of diffuser performance under both heating and cooling conditions. HVAC system designers should carefully select not only the diffusers but also air flow rate, supply air temperature and a control sequence that can achieve better air change effectiveness and thermal comfort with optimal use of energy under both cooling and heating modes. 


\begin{tabular}{l|c|c|c|c|c}
\hline \multirow{2}{*}{ Diffuser Type } & \multicolumn{2}{|c|}{$\begin{array}{c}\text { Recommended range } \\
\text { of } T_{0.25} / L \text { regarding } \\
\text { ADPI }\end{array}$} & \multicolumn{3}{|c}{$\begin{array}{c}\text { Range of } E \text { and } \varepsilon_{T} \text { within } \\
\text { recommended } T_{0.25} / L \text { regarding ADPI }\end{array}$} \\
\cline { 2 - 7 } & $\begin{array}{c}T_{0.25} / L \\
{[-]}\end{array}$ & $\begin{array}{c}\text { Loads } \\
{\left[\mathrm{W} / \mathrm{m}^{2}\right]}\end{array}$ & $\begin{array}{c}E \\
{[-]}\end{array}$ & $\varepsilon_{T}$ & Loads \\
& {$[-]$} & {$\left[\mathrm{W} / \mathrm{m}^{2}\right]$} \\
\hline
\end{tabular}

Heating

\begin{tabular}{l|c|c|c|c|c}
\hline Linear Slot Diffusers & $2.1-3.4$ & $30-40$ & $0.57-0.87$ & $0.65-0.75$ & $20-31$ \\
\hline $\begin{array}{l}\text { Round Ceiling } \\
\text { Diffusers }\end{array}$ & $1.4-2.1$ & $30-40$ & $0.68-0.85$ & $0.66-0.72$ & $24-30$ \\
\hline $\begin{array}{l}\text { Louvered Face } \\
\text { Diffusers without Lip }\end{array}$ & $2.4-3.3$ & $30-40$ & $0.66-0.81$ & $0.65-0.74$ & $26-33$ \\
\hline $\begin{array}{l}\text { Perforated Diffusers } \\
\text { Directional Pattern } \\
\text { (4way) }\end{array}$ & $2.4-2.9$ & $30-40$ & $0.56-0.72$ & $0.58-0.65$ & $27-30$ \\
\hline
\end{tabular}

Cooling

\begin{tabular}{l|c|c|c|c|c}
\hline Linear Slot Diffusers & $1.1-3.5$ & $25-50$ & $1.12-1.05$ & $1.11-0.98$ & $14-69$ \\
\hline $\begin{array}{l}\text { Round Ceiling } \\
\text { Diffusers }\end{array}$ & $0.5-2.3$ & $25-50$ & $1.08-1.03$ & $1.03-0.97$ & $17-66$ \\
\hline $\begin{array}{l}\text { Louvered Face } \\
\text { Diffuser with no lip }\end{array}$ & $1.0-3.3$ & $25-50$ & $1.05-0.98$ & $1.03-0.92$ & $17-62$ \\
\hline $\begin{array}{l}\text { Perforated Diffuser } \\
\begin{array}{l}\text { Directional Pattern } \\
\text { (4way) }\end{array}\end{array}$ & $0.7-3.0$ & $25-50$ & $1.16-0.98$ & $1.07-0.98$ & $17-63$ \\
\hline
\end{tabular}

Table 4.2: The range of air change effectiveness, $E$, and temperature effectiveness, $\varepsilon_{T}$, within the range of recommended $T_{0.25} / L$ in terms of $A D P I$. 


\subsection{Discussion on Variance of Local air Change Effectiveness in the Test Space}

The ASHRAE standard 129 (2002) requires measuring Local air Change Effectiveness, $E_{i}$, at a minimum of ten work stations. However, as results showed, the variances of $E_{i}$ were minimal when mixing ventilation with ceiling supply and return system was tested. Most of the differences found in the test space were close to the expected uncertainty of the experiment. In addition, previous research showed the presence of workstations (partition height: $1.9 \mathrm{~m}$, ceiling height: $2.9 \mathrm{~m}$ ) had no significant effects on the air distribution patterns, and influences of workstation layout to the ventilation efficiency were minimal (Shar et al. 1993). In addition, Lee's (2004) study showed the effects of internal partitions were low when the partition height was $60 \%$ of ceiling height.

It is implied that a more conventional evaluation will be possible with the reduced number of measuring points with mixing ventilation when partitions in the space are low enough to avoid obstructing air flow patterns in the targeted space.

\section{Correlation of Air Change Effectiveness $E$ and Temperature Effectiveness $\varepsilon_{T}$}

A lot of effort is required to conduct tracer gas tests in the field. Measuring temperature requires much less effort than the tracer gas test, and many of the building control and monitoring systems already measure temperature. The correlation found from this analysis may be useful to interpret overall air change effectiveness in a space where conducting a tracer gas test is not practical. However, careful consideration must be given to the HVAC system, especially the source of heating and cooling in the space. Krajcik et al. (2012) measured air change efficiency and temperature effectiveness in a test chamber with various combinations of radiant floor heating and mixing ventilation with air exchange rates of $0.5 \mathrm{hr}^{-1}$ and $1.0 \mathrm{hr}^{-1}$. Correlation of temperature effectiveness and air 
change efficiency was not observed from the study's experiments because an internal heating source might affect occupied zone temperature. 


\section{Chapter 5: Conclusion}

Experimental measurements in a full-scale test room were conducted with various types of diffusers, air flow rates and internal loads to evaluate the air change effectiveness and the temperature effectiveness. These experiments were conducted on both heating and cooling cycles, though there was an emphasis on the heating mode. The experiments of mixing ventilation also evaluated if a more practical evaluation of ventilation effectiveness could be made possible by using fewer measuring points.

All diffusers tested showed similar results, although each diffuser had a unique shape. Under the heating mode, the ranges of air change effectiveness, $E$, and temperature effectiveness, $\varepsilon_{T}$, were 0.56 to 0.87 and 0.58 to 0.75 , respectively within the recommended range of $T_{0.25} / L$ regarding ADPI. A significant decrease of $E$ was found to occur when $T_{0.25} / L$ was small. Both $E$ and $\varepsilon_{T}$ increased as $\Delta T$ became close to isothermal flow. Under the cooling mode, the ranges of $E$ and $\varepsilon_{T}$ were 0.98 to 1.12 and 0.92 to 1.11, respectively within the recommended range of $T_{0.25} / L$ regarding ADPI. Relatively good mixing was found under cooling conditions.

The studies provided fundamental diffuser performance data that considers both thermal comfort and ventilation effectiveness. The range capable of achieving good mixing under the heating condition was significantly smaller than the range for the cooling mode. Not just diffusers, but also other factors in an HVAC system such as air flow rate and supply air temperature should be carefully designed in all-air heating and cooling system with mixing ventilation in order to achieve good mixing and thermal comfort.

The results showed the vertical, horizontal and overall variance of local air change effectiveness was minimal. The variance of air change effectiveness in the 
occupied space of the room with ceiling diffusers was less than $16 \%$ in most of the cases, which is slightly larger than the experiments' uncertainty. Furthermore, the newly developed correlation between thermal effectiveness and air change effectiveness is considered to be a useful alternative method to interpret air change efficiency. 


\section{References}

ASHRAE. 2002. ANSI/ASHRAE Standard 129-1997, Measuring Air-Change Effectiveness. American Society of Heating, Refrigerating and Air- Conditioning Engineers, Inc.; Atlanta, GA

ASHRAE. 2009. ASHRAE. Handbook of fundamentals, chapter 57, Room Air Distribution. American Society of Heating, Refrigerating and Air- Conditioning Engineers, Inc.; Atlanta, GA.

ASHRAE. 2009. ANSI/ASHRAE Standard 113-2009, Method of testing for room air diffusion. American Society of Heating, Refrigerating and Air- Conditioning Engineers, Inc.; Atlanta, GA.

ASHRAE. 2010. ANSI/ASHRAE Standard 62.1-2010, Ventilation for Acceptable Indoor Air Quality. American Society of Heating, Refrigerating and Air- Conditioning Engineers, Inc.; Atlanta, GA.

Awbi H.B, and Gan G. 1993. Evaluation of the overall performance of room air distribution. Proceedings of Indoor air (3), 283-238.

Boyle Son R. 1899. Natural and artificial methods of ventilation. London.

Cao G.Y, Ruponen M, Jarek K. 2010. Experimental investigation of the velocity distribution of the attached plane jet after impingement with the corner in a high room. Energy Build, 42(6), pp.935-944.

Cao G, Awbi H, Yao R, Fan Y, Siren K, Kosonen R, and Zhang J. 2013. A review of the performance of different ventilation and airflow distribution systems in buildings. Building and Environment, 73, 171-186.

Clements C.D.J. 1975. Air conditioning and ventilation of buildings. Oxford, New York, Pergamon Press.

Cui S, Cohen M, Stabat P, and Marchio D. 2015, $\mathrm{CO}_{2}$ tracer gas concentration decay method for measuring air change rate. Building and Environment, 84, 162-169

Dietz R.N, Goodrich R.W, Cote E.A. and Wieser R.F. 1986. Detailed description and performance of a passive perfluorocarbon tracer system for building ventilation and air exchange measurement, Measured air leakage of buildings, STP 904. Trechsel H.R. and Lagus P.L. eds. American Society for Testing and Materials. West Conshohocken, PA.

Etheridge D, Sandberg M. 1996. Building Ventilation, Theory and Measurement, Wiley, New York, 471-473.

Fisk W.J, Prill R.J. and Steppanen O. 1989. A multi-tracer technique for studying rates of ventilation, air distribution patterns and air exchange efficiencies. Proceedings of 
Conference on Building Systems, Room Air and Air Contaminant Distribution, pp. 237-240.

Fisk W.J, Faulkner D, Sullivan D, and Bauman F. 1997. Air change effectiveness and pollutant removal efficiency during adverse mixing conditions. Indoor Air, 7, 5563.

Fortmann R.C, Nagda N.L. and Rector H.E. 1990. Comparison of methods for the measurement of air change rates and interzonal airflows to two test residences, Air change rate and airtightness in buildings, STP 1067, pp. 104-118. Sherman M.H. ed. American Society of Testing and Materials, West Conshohocken, PA.

Harrje, D.T, Dietz R.N, Sherman M, Bohac D.L, D'Ottavio T.W. and Dickerhoff D.J. 1990. Tracer gas measurement systems compared in a multifamily building, Air change rate and airtightness in buildings, STP 1067, pp. 5-12. Sherman M.H. ed. American Society for Testing and Materials, West Conshohocken, PA.

Khan J.A, Feigley C.E, Lee E, Ahmed M.R, and Tamanna S. 2006. Effects of inlet and exhaust locations and emitted gas density on indoor air contaminant concentrations. Building and Environment, 41(7), 851-863.

Krarti M. 2008. Energy efficient systems and strategies for heating, ventilating, and air conditioning (HVAC) of buildings. Journal of Green Build, 3(1), 44-55.

Krajcik M, Simone A, and Olesen B.W. 2012. Air distribution and ventilation effectiveness in an occupied room heated by warm air. Energy and Buildings, 55, 94-101.

Koestel A. and Tuve G.L. 1955. Performance and evaluation of room air distribution systems. ASHAE Transactions 61: 533

Lagus P, and Persily A.K. 1985. A review of tracer-gas techniques for measuring airflows in buildings. ASHRAE Transactions, 91 (2B), 1075.

Lee E, Khan J.A, Feigley C.E, Ahmed M.R, and Hussey J.R. 2007. An investigation of air inlet types in mixing ventilation. Building and Environment, 42(3), 1089-1098.

Lee H, Awbi H.B. 2004. Effect of internal partitioning on indoor air quality of rooms with mixing ventilation basic study. Build Environment, 39, pp.127-141.

Lee H, and Awbi H.B. 2004. Effect of internal partitioning on room air quality with mixing ventilation, statistical analysis. Renewable Energy, 29(10), 1721-1732.

Liu S, and Novoselac A. 2014. Lagrangian particle modeling in the indoor environment: a comparison of RANS and LES turbulence methods. HVAC\&R Res, 20(4), 480495.

Liu S, and Novoselac A. 2015. Air Diffusion Performance Index (ADPI) of diffusers for heating mode. Building and Environment, 87, 215-223. 
Liu S and Novoselac A. 2015. The Effect of Deflectors on Air Diffusion Performance Index (ADPI) of Adjustable Diffusers: Cooling Condition. Science and Technology for the Built Environment.

Liu S, and Novoselac A. 2016. Expansion and updating of the air diffusion performance index method (RP 1546). ASHRAE Research Project Report, TC 5.3, Indoor Air Distribution.

Miller P.L. and Nevins R.G. 1969. Room air distribution with an air distributing ceiling Part II. ASHRAE Transactions 75: 118.

Miller P.L. and Nevins R.G. 1970. Room air distribution performance of ventilation ceilings and cone-type circular ceiling diffusers. ASHRAE Transactions 76 (1), 186.

Miller P.L. and Nevins R. 1972. An analysis of the performance of room air distribution systems. ASHRAE Transactions 78 (2).

Miller P.L. 1971. Room air distribution performance of four selected outlets. ASHRAE Transactions 77(2), 194.

Miller P.L. and Nash R.T. 1971. A further analysis of room air distribution performance. ASHRAE Transactions 77(2), 205.

Miller P.L. 1979. Design of room air diffusion systems using the air diffusion performance index (ADPI). ASHRAE Journal 10, 85.

Muller D, Kandzia C, Kosonen R, Melikov A.K, and Nielsen P.V. 2013. Mixing ventilation, guidebook on mixing air distribution design, No.19. REHVA guidebook.

Mundt I, Mathisen M.H, Nielsen V.P, and Moser A. 2004. Ventilation effectiveness, No. 2, REHVA guidebook.

Nielsen PV. 1991. Models for the prediction of room air distribution. Proceedings of the 12th AIVC conference, (1), pp. 55-71.

Nevins R.G. and Miller P.L. 1972. Analysis, evaluation and comparison of room air distribution performance-a summary. Research Report, ASHRAE RP-55 and 88.

Novoselac A, and Srebric J. 2003. Comparison of air exchange efficiency and contaminant removal effectiveness as IAQ indices. ASHRAE Trans 109(2), pp. 339-349.

Offermann F.J, and Int-Hout D. 1989. Ventilation effectiveness measurements of three supply/return air configurations. Environment International, 15(6), 585-592.

Persily A.K. and Axley J. 1990. Measuring airflow rates with pulse tracer techniques, Air change rate and airtightness in buildings, STP 1067, pp.31-51. Sherman M.H. ed. American Society for Testing and Materials, West Conshohocken, PA. 
Platt G, Li J, Li R, Poulton G, James G, and Wall J. 2010. Adaptive HVAC zone modelling for sustainable buildings. Energy Build, 42(4), 412-421.

Rydberg J. and Norback P. 1949. Air distribution and draft. ASHRAE Transactions 55: 225

Sandberg M, Blomqvist C, Sjöberg M. 1986. Efficiency of general ventilation systems in residential and office buildings -concepts and measurements. Goodfellow HD, Ventilation, 85,

Sandberg M, Wiren B, Claesson L. 1992. Attachment of a cold plane jet to the ceiling length of recirculation region and separation distance. Proceedings of roomvent. pp. 489-99.

SHASE 2010. SHASE Standard 115-2010, Field Measurement Methods for Ventilation Effectiveness in Rooms, Society of Heating, Air-Conditioning and Sanitary Engineers of Japan.: Tokyo

Shaw C.Y, Zhang J.S, Said M.N, Vaculik F, and Magee R.J. 1993. Effect of air diffuser layout on the ventilation conditions of a workstation, Part 1: Air distribution patterns, Part 2: Air change efficiency and ventilation efficiency. ASHRAE Transactions, 99(2), 125-143.

Sherman M.H. and Grimsrud D.T. 1980. Infiltration-pressurization correlation Simplified physical modeling. ASHRAE Transactions, 86 (2), 778.

Sherman M.H. 1989. Uncertainty in airflow calculations using tracer gas measurements. Building and Environment, 24(4), pp.347-354.

Sherman M.H. 1989. On the estimation of multizone ventilation rates from tracer gas measurements. Building and Environment, 24 (4), pp.355-362.

Sherman M.H. 1990. Tracer gas techniques for measuring ventilation in a single zone. Building and Environment, 25(4), pp.365-374.

Sinha S.L, Arora R.C, and Roy S. 2000. Numerical simulation of two dimensional room air flow with and without buoyancy. Energy and Buildings, 32, 121-129.

Straub H.E, Gilman S. F. and Konzo S. 1956. Distribution of air within a room for yearround air conditioning -Part I. University of Illinois Engineering Experiment Station Bulletin: 435.

Straub H.E, and Chen M.M. 1957. Distribution of air within a room for year-round air conditioning-Part II. University of Illinois Engineering Experiment Station Bulletin: 442.

Tomasi R, Krajcik M, Simone A, and Olesen B.W. 2013. Experimental evaluation of air distribution in mechanically ventilated residential rooms: Thermal comfort and ventilation effectiveness. Energy and Buildings, 60, 28-37. 
Vakiloroaya V, Samali B, Fakhar A, and Pishghadam K. 2014. A review of different strategies for HVAC energy saving. Energy Convers Management, 77, 738-754.

Walker I.S. and Wilson D.J. 1993. Evaluating models for superposition of wind and stack effects in air infiltration. Building and Environment, 28(2), pp.201-210.

Walker I.S. and Forest T.W. 1995. Field measurements of ventilation rates in attics. Building and Environment, 30(3), pp.333-347.

$\mathrm{Wu} \mathrm{W}$, and Lin Z. 2015. An experimental study of the influence of a walking occupant on three air distribution methods. Building and Environment, 85, pp. 211-219. 


\section{Vita}

Hideyuki Amai was born in Tokyo, Japan. After completing his work at Waseda University High School, Tokyo, Japan, in 2000, he entered Waseda University. He received the degree of Bachelor of Architecture from Waseda University in March 2004. After two-year research on built environment, he received the degree of Master of Engineering major in Architecture from Waseda University in March 2006. During the

following years, he was employed as a Mechanical Design Engineer at Obayashi Corporation. In August, 2014, he entered the Graduate School at the University of Texas at Austin.

Email: amai.hideyuki@gmail.com

This manuscript was typed by the author. 